\title{
On organisational involvement and collaboration in W3C standards through editorship
}

\author{
Jonas Gamalielsson * [D and Björn Lundell
}

\begin{abstract}
Over time, a number of open standards have been developed and implemented in software for addressing a number of challenges, such as lock-in, interoperability and longevity of software systems and associated digital artefacts. An understanding of organisational involvement and collaboration in standardisation is important for informing any future policy and organisational decisions concerning involvement in standardisation. The overarching goal of the study is to establish how organisations contribute to open standards development through editorship. Specifically, the focus is on open standards development in the World Wide Web Consortium (W3C). Through an analysis of editorship for all W3C recommendations we contribute novel findings concerning organisational involvement and collaboration, and highlight contributions from different types of organisations and countries. We make five principal contributions. First, we establish an overall characterisation of organisational involvement in W3C standardisation. Second, we report on organisational involvement in W3C standardisation over time. Third, we establish how different organisations, organisation types, and countries are involved in W3C technologies. Fourth, we report on organisational involvement in relation to standard development time. Fifth, we establish how organisations collaborate in W3C standardisation through social network analysis.
\end{abstract}

Keywords: Organisations, Involvement, Collaboration, W3C, Standards, Editorship

\section{Introduction}

Over time, a number of Information and Communication Technology (ICT) standards have been developed and deployed for addressing a number of challenges in the area of software systems, including interoperability and longevity of systems [30]. In the area of ICT standardisation there are a number of efforts and different (sometimes conflicting) interests amongst stakeholders involved. Previous research shows that "companies are the most important and typically the most powerful stakeholders in (ICT) standards setting" [23]. Further, it has also been argued that "the absence of important players may lead to inadequate standards" [22]. In addition, previous research reports that some companies "aim to control the strategy of" a standardisation organisation, whereas other merely participate [23].

\footnotetext{
* Correspondence: jonas.gamalielsson@his.se

University of Skövde, P.O. Box 408SE-54128 Skövde, Sweden
}

Many ICT standards are implemented in software (including several open source implementations), and in some cases open source implementations have evolved into standards (e.g. [1, 2]). However, previous research shows that some standards may not be implemented in open source software due to inability to clarify conditions for use of standard essential patents which are controlled by some of the organisations contributing to development of those specific standards [32].

Challenges for ICT standardisation have also been recognised by policy makers and organisations developing standards. For example, the ICT rolling plan is an ongoing effort within the EU which recognises the importance of organisational involvement in standardisation for innovation [11] and there are also policy initiatives within the EU which recognise the importance of open standards [10]. Similarly, there are a number of national policy initiatives, such as the national policy for open standards in the U.K. [42, 43]. Further, amongst organisations developing standards there are also efforts for how to 
improve ICT standardisation such as initiatives for considering open source work practices in standardisation addressed in recent workshops organised by ETSI $^{1}$ (European Telecommunications Standards Institute) and ANSI $^{2}$ (American National Standards Institute).

From this it is evident that understanding organisational involvement and collaboration in standardisation is a challenge and is important for informing any future policy and organisational decisions on involvement in standardisation. To address this challenge the overarching goal of the study is to establish how organisations contribute to open standards development through editorship. Specifically, the focus is on standards development in W3C. Through an analysis of editorship for all W3C standards we investigate organisational involvement and collaboration, and highlight involvement in development of standards by different types of organisations and countries for headquarter of each organisation. We make five principal contributions. First, we establish an overall characterisation of organisational involvement in W3C standardisation. Second, we report on organisational involvement in W3C standardisation over time. Third, we establish how different organisations, organisation types, and countries are involved in W3C technologies. Fourth, we report on organisational involvement in relation to standard development time. Fifth, we establish how organisations collaborate in $\mathrm{W} 3 \mathrm{C}$ standardisation.

We focus on W3C standardisation since it has been claimed that W3C standards constitute an exemplar of open standards [13] and are widely deployed in software systems. All W3C standards are written in English and all communication is in English. In fact, W3C has adopted a work practice inspired by OSS (Open Source Software) development $[18,33]$, and work according to an open model with respect to intellectual property rights. This, in turn, facilitates participation from different types of companies and other organisations. There is limited knowledge concerning details on organisational involvement and collaboration in open standards development. To the best of our knowledge, this study contributes novel findings from the first comprehensive analysis of organisational involvement (through editorship) in all standards provided by W3C.

The rest of this paper is organised as follows. We present a background (Section 2). Thereafter we present research approach (Section 3), results and analysis (Section 4), discussion (Section 5), followed by conclusions and future work (Section 6).

\section{Background}

2.1 On standardisation and standardisation organisations Over the years, the term "standard" has been used under various different meanings by different stakeholders and stakeholder groups in area of ICT. Amongst practitioners, the standard concept often cause confusion in discussions and there is often a lack of clarity concerning exactly what is referred to when the term "standard" is used in the ICT-area (see e.g. [29]). The first use of the standard term dates back to $1138 \mathrm{AD}$ when "a king was the only creator of a standard" ([26], p. 25).

Today, there are many different types of organisations and consortia developing and promoting standards in a number of different contexts. At international level, the International Organization for Standardisation (ISO) promotes many different standards in the area of ICT. Similarly, at national level, there are a number of organisations promoting national standards, such as the BSI which is the oldest national standardisation organisation being established in 1901. As the National Standards Body of the UK they promote "British standards". Overall, there exist hundreds of standards bodies and fora [9] that develop, promote, and maintain standards. Numerous stakeholders that represent a range of different organisations (including individual ICT-companies, vendor consortia, user organisations, and public sector organisations) are involved in and affected by standards at international, national, and local levels. In essence, standards are in many cases associated with nonmandatory agreements between different stakeholders and organisations. For example, the BSI (British Standards Institution) states that:

"a standard is an agreed, repeatable way of doing something. It is a published document that contains a technical specification or other precise criteria

designed to be used consistently as a rule, guideline, or definition" [6].

Besides formally recognised standardisation organisations (such as ISO, BSI, and other corresponding national organisations), there are also other organisations focusing on specific areas. Examples of such organisations are the World Wide Web Consortium (W3C) and the Internet Engineering Task force (IETF) that work on developing and promoting standards that relate to their specific expertise. In addition, many standards are being developed and promoted by different consortia (e.g. European Computer Manufacturers Association (ECMA) and Organization for the Advancement of Structured Information Standards (OASIS)) in the area of ICT. Standards from some of these consortia have been broadly adopted and have also been recognised and adopted by ISO for publication as formal ISO-standards. It is important to recognise that consortium standards do not have the same status as 
formal standards concerning whether a standard can be recognised and accepted in the rules for procurement in the public sector.

Standards from different standardisation organisations are provided under different conditions ${ }^{3}$, including royalty-free ${ }^{4}$ and Reasonable and Non-Discriminatory (RAND/FRAND) terms [3]. In essence, RAND/FRAND terms "refers to a commitment to provide a license for compensation" ([3], p. 14). Moreover, it is important to note that the development of web standards is a complex process which requires a variety of different technical, managerial and social skills. In some cases, appointments of individuals as editors for a standard may cause tension and unease amongst participants and their respective organisations [40].

\section{$2.2 \mathrm{~W} 3 \mathrm{C}$}

W3C (World Wide Web Consortium) is "an international community where Member organizations, a full-time staff, and the public work together to develop Web standards" [44]. With its European origin in the early 1990s at CERN (Conseil Européen pour la Recherche Nucléaire), the organisation was founded at the Massachusetts Institute of Technology (MIT) in 1994, and has grown from 140 members in 1996 [20] to 427 members at time of writing [45].

Individuals and all types of organisations can become members (including commercial, educational, and governmental entities). Funding stems from membership fees, research grants and other types of public and private funding, sponsorship, and donations. There are some key components in the organisation of the standardisation process. One of these is the advisory committee, which has one representative from each W3C member and performs different kinds of reviews in the process of standardisation, and also elects an advisory board and the technical architecture group (which primarily works on web architecture development and documentation). Further, the W3C director and CEO assess consensus for decisions of W3C-wide impact. There is also a set of charted groups (working groups (WGs), interest groups, community groups, and coordination groups) consisting of member representatives and invited experts, which assist in the creation of web standards, guidelines, and supporting materials. W3C standards evolve through different stages through work in these charted groups (working draft, candidate recommendation, proposed recommendation, and W3C recommendation). "W3C recommendation" represents the most mature development stage, and indicates that the standard is ready for deployment and widespread use.

Development of web standards and their implementations have been characterised by 'openness' in terms of development, use, and provision of such technology. The decision not to patent underlying technology has promoted a culture of free license rights for developed web infrastructure [3]. In fact, the new patent policy adopted by W3C in 2003 is considered as "an extremely license fee intolerant Patent Policy" ([3], p. 27). Further, the W3C is seen as a "prime example for how Open Standards can boost innovation are the internet and the world wide web." ([13], p. 6). Similar as for the $\operatorname{IETF}^{5}$, it has been claimed that the W3C is "broadly open to interested participants" ([38], p. 27). It is also argued that such standards constitute "a major driver for growth - both on the global scale but also regarding the many small and medium-sized enterprises everywhere that prosper because of the internet and because of implementing the standards. Included are web hosting shops, web design shops, web shops themselves, etc. Open Standards are at the core of this. They promoted the biggest boost in innovation we have seen in the last decades" ([13], p. 6).

\subsection{On the editor role}

The role of leadership positions in standardisation (e.g. the editor role) is central as expressed in the following: "Holding leadership positions in standardization organizations has also been identified as an indicator of influence over the standardization process, as leadership positions can strengthen a firm's social capital within a standardization organization" and "quantifications of editorial and authorial positions within standards setting organizations have been deemed to indicate meaningful influence of standardization processes" [8]. It has also been claimed that "not all stakeholders are equal and neither are all members of a WG. At this level, certain roles may give the opportunity to influence the standardisation process (for instance, document editor or WG Chair; see e.g. [39])" [25].

The importance of the editor and editorial group for achieving an efficient standardisation process has been highlighted in a study where "several interviewees mentioned the importance of the editor and the editorial process. The position of editor seems to have particular importance in today's standards arena. Some suggested that the real delay in standard's development lies not in the balloting procedure, but in the intervening period when the document is supposedly coming together. A good editor or editorial group greatly enhances the standards process and should therefore be sought out and encouraged" [39]. The same study also highlights that the editor role can be challenging and requires special skills and flexibility: "Unfortunately, it seems that the task of correcting hundreds of pages of material between 
committee meetings is causing high attrition among editors, as they have trouble defending to their superiors at home additional time spent working on the document. It is not easy to identify individuals with a mastery of language and a desire to oversee the assembly of a report. They need a degree of freedom that allows them to work diligently towards completion of the document. It would seem that training in editing might be offered to interested members along with appropriate recognition in the process. Chairs should be alert for candidates for the editorial role" [39].

Further, previous research shows that the role as editor for a standard is an important role and sometimes there are stark tensions between different commercial interests related to development of a specific W3C standard [7]. From experiences of W3C standardisation it seems clear that the editor role in W3C is a substantial commitment: "Participating in a WG may take up to $8 \mathrm{~h}$ a week (averaged over the year, i.e., including $\mathrm{ftf}$ meetings), especially if you are editor of one or more specifications or chairing the group" [5].

\subsection{Previous research}

There are studies that address organisational involvement in open source projects but without addressing standards or their implementations. One such study explored organisational contributions to source code repositories over time for the open source modelling tools Topcased and Papyrus [16] and a different study reported results on organisational contributions to mailing lists for the open source project Nagios through analysis of email address subdomains [15]. Other studies explore organisational collaboration in specific open source communities through approaches involving social network analysis [28, 41]. There are also studies focused on organisational aspects, for example addressing different motivations for firms to participate in open source projects (e.g. [4]), how firms engage in open source projects under different governance models (e.g. [36]), community building aspects in communities sponsored by organisations (e.g. [47]), and emerging involvement of professional and commercial organisations in OSS [12]. However, none of these studies on organisational aspects explicate how the actual organisational participation occurs in concrete cases.

There are a few closely related studies. One of these explored Drupal and its use of the software standards RDFa, CMIS and OpenID [17] without considering organisational influences. Further, another study focused on influences between implementations of the PDF format and PDF standardisation [14]. Further, one study investigated influences between W3C RDFa and the Drupal implementation of RDFa through use of issue trackers [33]. There is also an in-depth study of organisational influences in the W3C RDFa standard and its implementation in Drupal [18]. A different study analysed communication patterns in W3C working groups [19]. In that study, collaborative interaction networks (COINS) were examined through analysis of email archives for some of the W3C working groups. However, none of these studies present an overall picture of organisational involvement in all standards for a major standardisation organisation. Hence, this motivates a comprehensive investigation of organisational involvement in W3C standards.

\section{Research approach}

By conduct of a systematic investigation of editorship for all W3C standards that had reached the status "W3C recommendation" at time of data collection (31 Jul. 2016), we analysed organisational involvement and collaboration in W3C. The investigation comprises five parts. For all five parts of our approach, we highlight involvement in development of standards for different organisations, types of organisations and countries for headquarter of each organisation.

For the first through fourth part of our approach we establish an overall characterisation of organisational involvement in W3C standardisation using an explorative approach involving descriptive statistics. Specifically, the first part involves calculation and presentation of: number of standards and organisations contributing to standards in $\mathrm{W} 3 \mathrm{C}$ standardisation, distribution of number of organisations involved as editors in W3C standards, number (and proportion) of standards for the top 15 organisations, number (and proportion) of standards for organisation types, and number (and proportion) of standards for the top 15 countries.

In a second part, we report on organisational involvement in W3C standardisation over time. Specifically, the second part involves calculation and presentation of: involvement in number of standards released over time for the top 15 organisations, involvement in number of standards released over time for organisation types, and involvement in number of standards released over time for the top 15 countries.

In a third part, we establish how different organisations, organisation types, and countries are involved in W3C technologies. Specifically, the third part involves calculation and presentation of: top 5 technologies for the top 15 organisations, intersection of technologies for top two through top 15 organisations, top 5 technologies for the 10 organisation types, intersection of technologies for top two through top 10 organisation types, top 5 technologies for the top 15 countries, and intersection of technologies for top two through top 15 countries. 
In a fourth part, we report on organisational involvement in relation to standard development time. Specifically, the fourth part involves calculation and presentation of: distribution of development time for W3C standards, development time intervals for W3C standards, number of standards in development over time, top $15 \mathrm{~W} 3 \mathrm{C}$ standards in terms of short development time, top $15 \mathrm{~W} 3 \mathrm{C}$ standards in terms of short development time, Pearson correlation for establishing relationship between number of organisations (at editor level) and the development time, box plot illustrating development time statistics for organisation types, statistical significance for comparisons of development time for organisation types (through use of the non-parametric Mann-Whitney one-sided $\mathrm{u}$-test and the one-sided alternative null one-sided null hypothesis $\operatorname{PROB}(X>Y)>1 / 2$, where $X$ and $Y$ are the samples), box plot illustrating development time statistics for countries, and statistical significance for comparisons of development time for countries (through use of the same Mann-Whitney test as for organisation types).

Finally, in a fifth part, we establish how organisations collaborate in W3C standardisation by undertaking social network analysis involving fundamental network metrics. A collaboration network at organisational level can be formally defined as a graph $G o=(V o, E o)$, where $V o$ is the set of nodes representing the organisations that contribute as editors to W3C standards and Eo is the set of edges identifying the connections between two organisations if both have participated as editors in the same standard. Edge weight is increased by one for each standard jointly participated in. Similarly, a collaboration network at organisation type level can be formally defined as a graph $G t=(V t, E t)$, where $V t$ is the set of nodes representing the mapped organisation types for organisations that contribute as editors to W3C standards and $E t$ is the set of edges identifying the connections between two organisation types if both have participated as editors in the same standard. Edge weight is increased by one for each standard jointly participated in. In the same manner, a collaboration network at country level can be formally defined as a graph $G c=(V c$, $E c$ ), where $V c$ is the set of nodes representing the mapped countries for organisations that contribute as editors to W3C standards and $E c$ is the set of edges identifying the connections between two countries if both have participated as editors in the same standard. Edge weight is increased by one for each standard jointly participated in. Self-loops have been removed for nodes in all three collaboration networks. The network metrics degree centrality and weighted degree centrality were used in the analysis. Other metrics (including e.g. betweenness centrality, closeness centrality, and eigenvector centrality) were considered, but were ruled out as the metrics used (degree centrality and weighted degree centrality) revealed to be sufficient for capturing the most fundamental collaboration aspects in the networks studied.

Data for standards (standard name, date of release, and editors \& associated organisations) were manually collected from the W3C website 6 . Mapping of organisation type and country of headquarter for each organisation was established through a systematic manual search for organisation names by use of LinkedIn ${ }^{7}$, Wikipedia ${ }^{8}$, or (as a last resort) Google search ${ }^{9}$. Mapping of standards to $\mathrm{W} 3 \mathrm{C}$ technologies was done using the categorisation of standards by $\mathrm{W} 3 \mathrm{C}^{10}$. In this categorisation, one standard may be categorised to several different technologies. The categorisation of technologies used for the study is officially recognised by the W3C and is publicly available, and therefore considered relevant. Data on development time for standards was collected through use of the W3C API ${ }^{11}$, where the date for the first release (typically a working draft) and the latest release (the recommendation) of a standard was collected and used for calculations. Custom made scripts were used throughout in order to parse and analyse the data and derive results. Prior to data processing, collected data were manually cleansed in order to remove redundancy and inconsistency. Social networks were visualised and analysed through use of the Gephi $^{12}$ software package (version 0.9.1).

\section{Results and analysis}

This section presents the results from the study and associated analysis. Table 1 presents the main results from our observations concerning organisational involvement and collaboration in W3C standards through editorship as reported in the following subsections.

\subsection{Characterisation of organisational involvement in W3C standardisation}

There are (at time of data collection) 265 specific W3C standards which have reached "W3C recommendation" status. The first of these standards was published 14 Jan. 1997 and the latest 23 Jun. 2016. 234 organisations in total have contributed to W3C standardisation through editorship in standards during almost 20 years. Figure 1 shows the distribution of number of organisations for the standards. There are on average 3,2 organisations contributing through editorship to each of these standards (with a minimum of zero organisations and a maximum of 21 organisations). It can be observed that $82 \%$ of the standards (216 of the 265 standards) have more than one organisation represented in the editorial board, and 17\% (45 standards) have at least five organisations represented. 
Table 1 Main themes for investigation with associated main results

Characterisation of organisational involvement in W3C standardisation

Characterisation of organisational involvement over time

Organisational involvement in different technologies

Organisational involvement in relation to standard development time

Organisational collaboration in W3C standardisation
- A standardisation organisation and larger enterprises are dominating involvement overall with respect to editorship.

- The United States and other countries where the majority of citizens are native English speakers dominate involvement.

-W3C standard development has proceeded over approximately 20 years.

- A strong growth in number of standard development projects has been experienced over time.

- Larger enterprises have been most extensively involved over time compared to other organisation types.

- The United States have been continuously involved in standards released since the beginning of W3C standardisation.

- Larger enterprises dominate by contributing primarily to the most highly ranked technologies.

- Larger enterprises are alone editors in standards for 12 of 89 technologies

- Universities are alone editors in standards for two technologies.

- The United States dominate by contributing primarily to the most highly ranked technologies.

- The United States are alone editors in standards for 17 of 89 technologies.

- Great Britain are alone editors in standards for two technologies.

- Development time for standards is diversified and spans from a couple of months to 15 years for different standards.

- There are significant differences in development time for standards involving different organisation types and countries.

- Standards involving research institutes have the shortest development time.

- Standards involving universities have the longest development time.

- There is extensive collaboration between different organisations, types of organisations, and countries.

- Larger enterprises have the most extensive collaboration with other organisation types.

- Larger enterprises and universities collaborate most extensively.

- The United States have the most extensive collaboration with other countries.

- The United States and Great Britain collaborate most extensively.

- The majority of organisations with extensive involvement have extensive collaboration.

- The level of involvement and collaboration is similar for the different organisation types.

- All countries with extensive involvement have extensive collaboration.

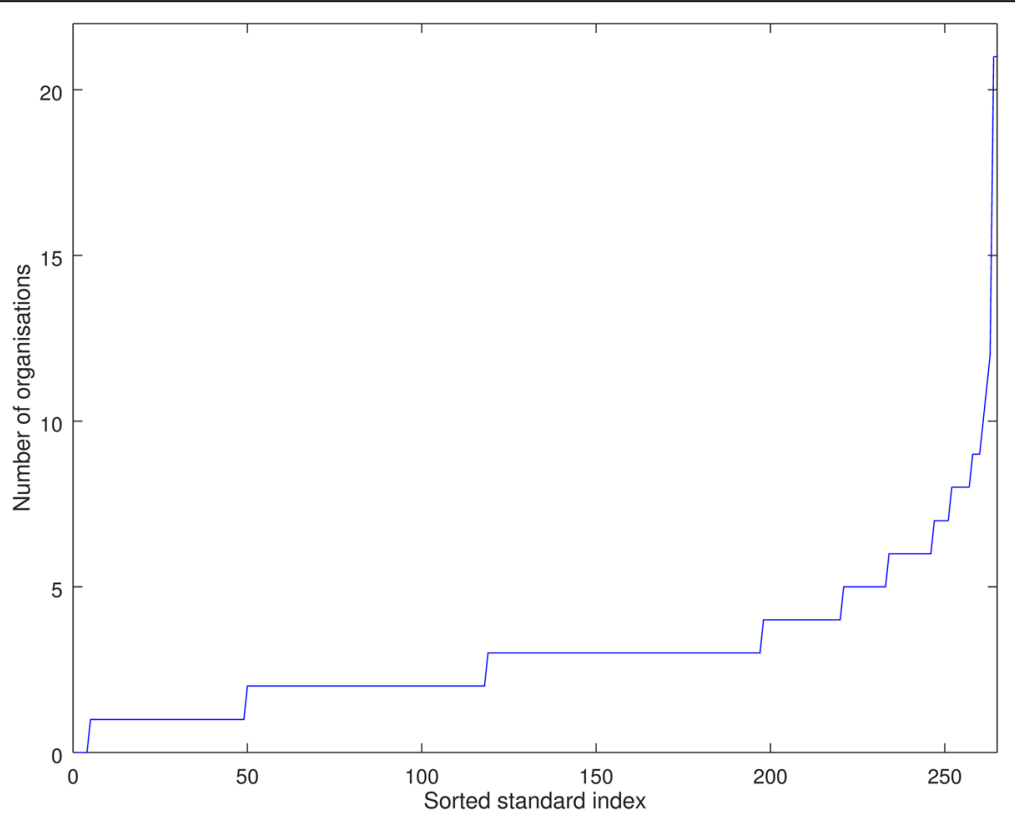

Fig. 1 Distribution of number of organisations involved as editors in W3C standards 
Further, there are four standards without any organisation represented in the editor team.

Figure 2 shows the number (and proportion) of standards for the 15 organisations that through editorship are involved in the largest number of standards (O1 through O15). An organisation has been mapped to one of the following organisation types: Micro Enterprise (MiE, an enterprise with 1-9 employees), Small and Medium-sized Enterprise (SME, an enterprise with 10-250 employees), Larger Enterprise (LE, an enterprise with more than 250 employees), Research Institute (RI), University (Uni), Standardisation Organisation (SO), Non-profit Organisation (NPO), Public Broadcasting Service (PBS), and Hospital $(\mathrm{H})$. The same mapping scheme was used in Gamalielsson et al. [18]. Further, the country of the organisation's headquarter is also stated in the figure (according to the ISO 3166-1 alpha-2 character scheme ${ }^{13}$ ). In Fig. 2, it can be observed that the vast majority of contributing organisations (12 out of 15) are larger enterprises. Further, we note that amongst the top 15 organisations there are 13 from countries where the majority of citizens are native English speakers ${ }^{14}$ (United States, Great Britain, and Ireland). In particular, the United States is clearly dominating in terms of involvement in number of standards.

The number (and proportion) of standards for different organisation types is illustrated in Fig. 3. It can be noted that larger enterprises are clearly involved in the largest number of standards. An interesting observation is that small and medium-sized enterprises and micro enterprises are involved in a relatively large number of standards (55 and 52 , respectively).
Figure 4 shows the number and proportion of standards for the top 15 countries involved in W3C standardisation through editorship. In total there are 26 countries involved (in descending order in terms of involvement these countries are United States, Great Britain, Germany, Canada, Ireland, Japan, France, Finland, Norway, Netherlands, Spain, Sweden, Italy, Austria, Switzerland, Australia, Belgium, South Korea, Thailand, Chile, China, Russia, Czech Republic, Greece, Israel, and United Arab Emirates). Of the remaining 11 (of the 26) countries (excluded from Fig. 4) Australia is involved in four standards; Belgium, South Korea, and Thailand are involved in three; Chile, China, and Russia are involved in two; and Czech Republic, Greece, Israel, and United Arab Emirates are involved in only one standard. Another observation from Fig. 4 is that Unites States is clearly dominating overall and involved in the vast majority of all W3C standards. It can also be noted that of the 26 countries involved, the majority of citizens are native English speakers in 4 of the top 5 countries. We also note that for the remaining 22 countries (except Australia), English is not an official language.

In summary, it is clear that a standardisation organisation and larger enterprises are dominating involvement in W3C standards overall with respect to editorship. The observation that small and medium-sized enterprises and micro enterprises are involved in a relatively large number of standards indicates that participation in standardisation in W3C is open and inclusive. This is in-line with earlier findings which suggest that "contributions to W3C standards have a low barrier for entry and participation" [18]. We note that the United States and other countries where the majority of citizens are native English speakers

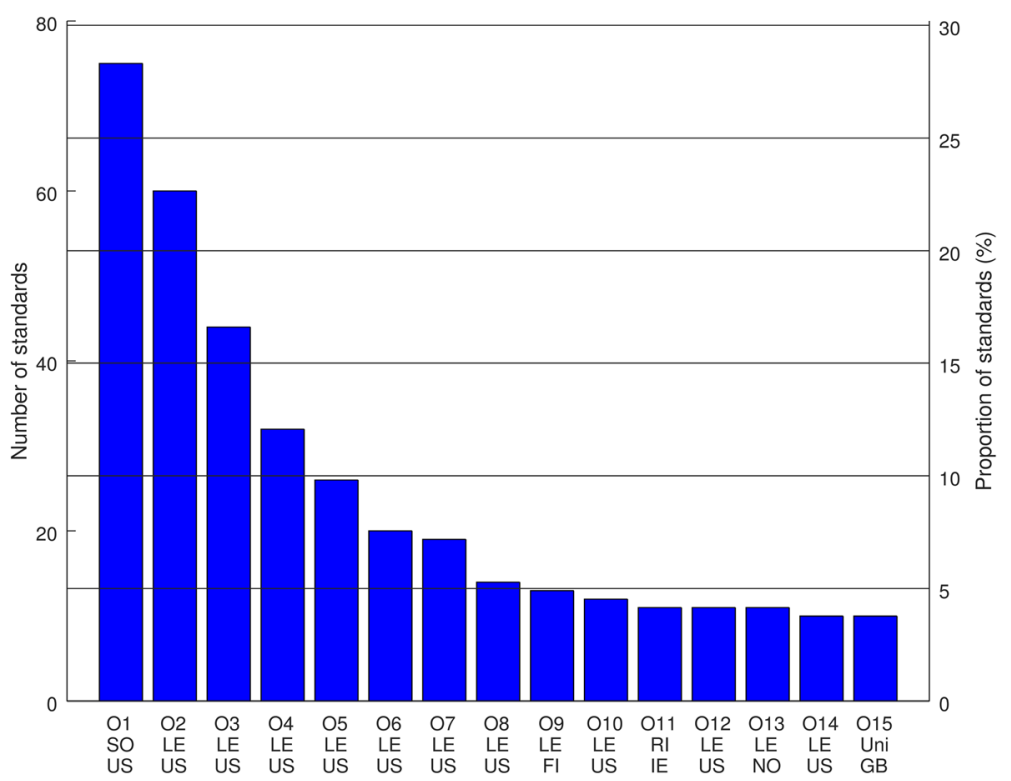

Fig. 2 Number (and proportion) of standards for the top 15 organisations 


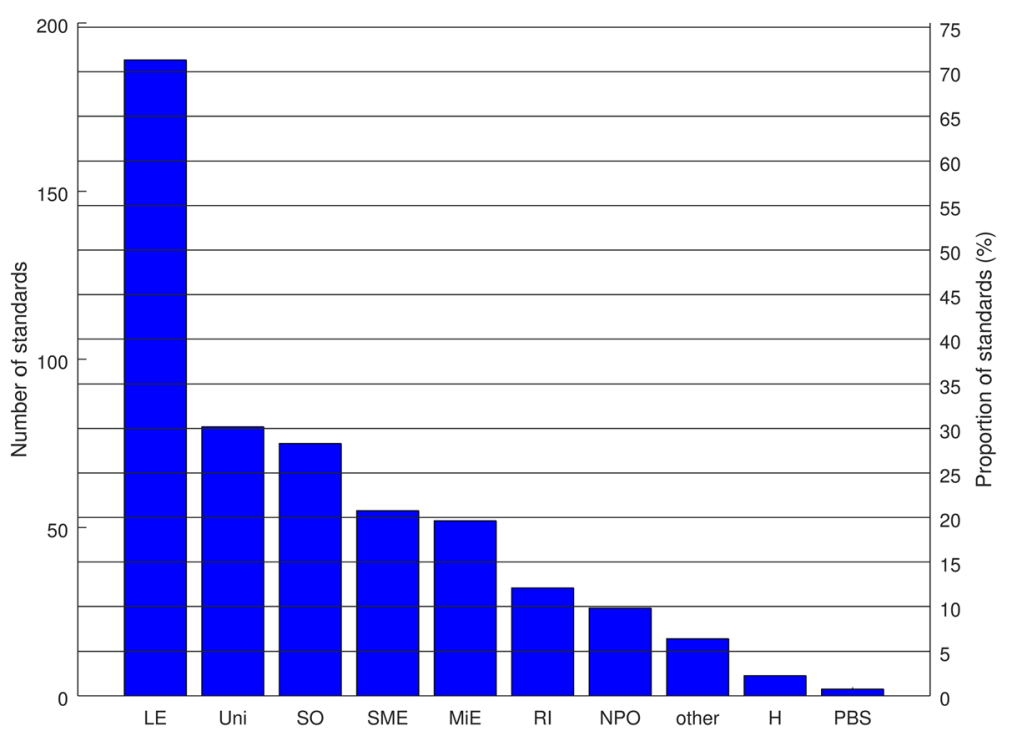

Fig. 3 Number (and proportion) of standards for organisation types

dominate involvement in W3C standards with respect to editorship. Further, our results show rather limited involvement in W3C standardisation through editorship from Asian organisations compared to involvement from US and Europe, something which is in contrast with their corresponding involvement in IETF standardisation ([8], p. 915). Amongst Asian countries, Japanese organisations are the most actively involved in W3C standardisation, whereas related research shows that Chinese authors of IETF documents are more active than Japanese ([8], p. 926). Further, it has been reported that China is extensively involved in development of ITU-T standards, whereas there is limited involvement in development of IETF, OASIS, and W3C standards [24] despite a large number of users.

\subsection{Characterisation of organisational involvement over time}

Figure 5 illustrates involvement in number of standards released over time for the top 15 organisations, where the colour of each cell indicates number of standards. We note that only the top organisation has been continuously involved in standards released since the beginning of W3C standardisation. It can also be

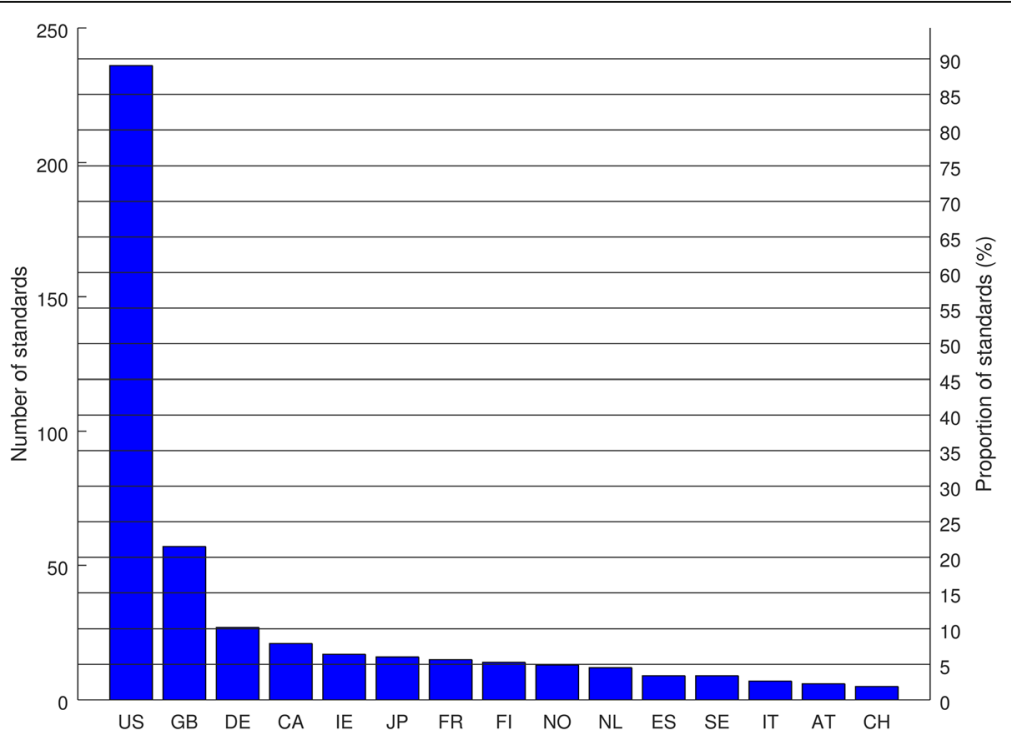

Fig. 4 Number (and proportion) of standards for the top 15 countries 


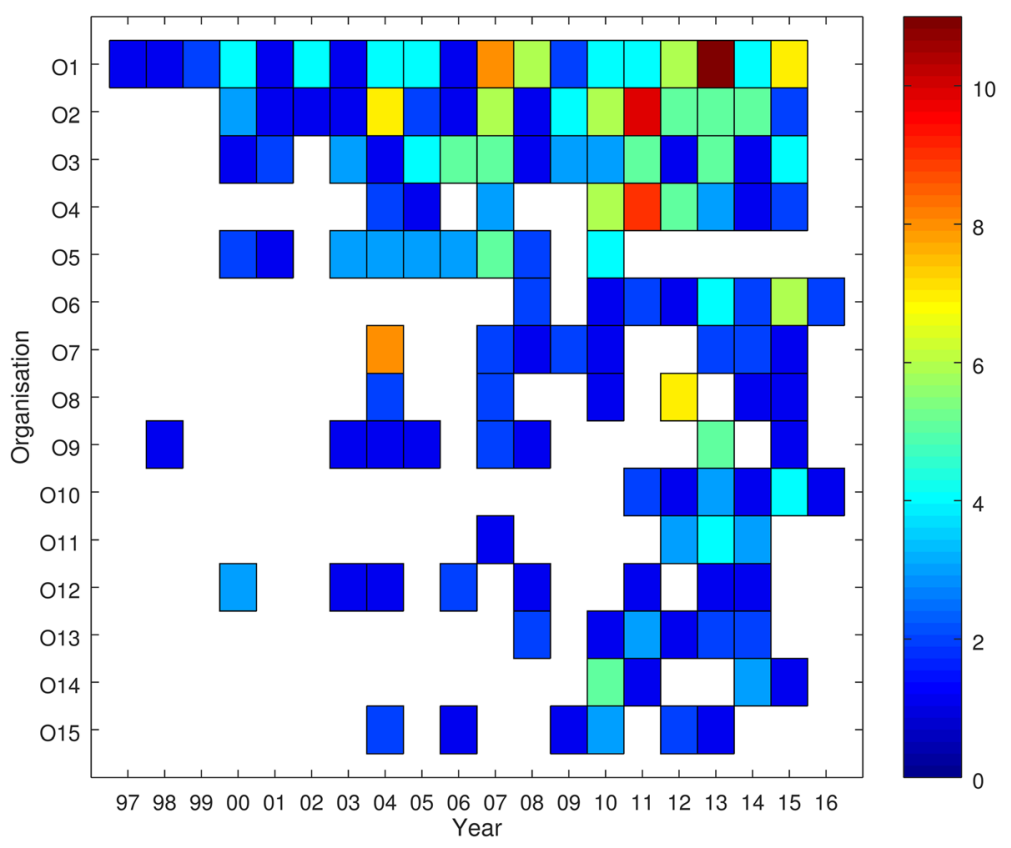

Fig. 5 Involvement in number of standards released over time for the top 15 organisations

observed that organisations amongst the top 15 have been involved in standards released during a varying number of the total 20 years of W3C standardisation ${ }^{15}$ (for O1 through O15 for standards released during 19, $16,15,9,9,8,8,6,8,6,4,8,6,4$, and 6 years, respectively) and with a varying amount of involvement and degree of continuity.
Involvement in number of standards released over time for the different organisation types is shown in Fig. 6 (listed in the same order as in Fig. 3). We note that larger enterprises have initially been involved in W3C standardisation for standards released in 1998 and continuously since year 2000. Further, it can be observed that organisations of different organisation

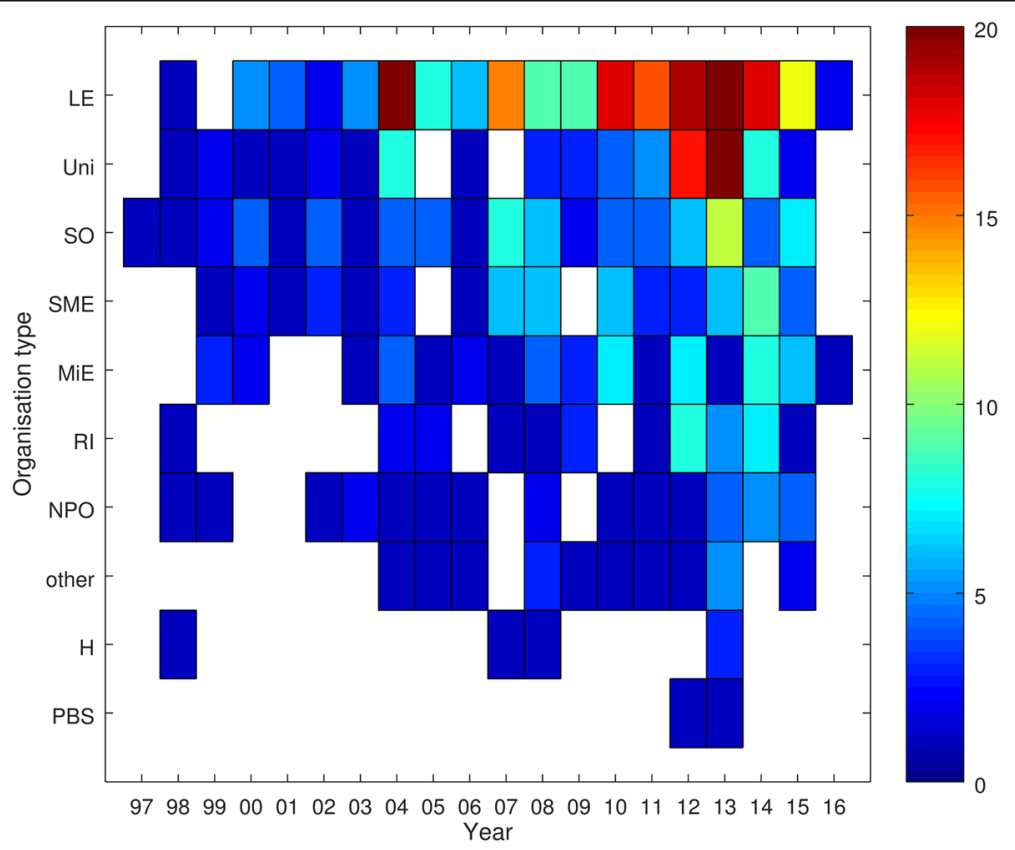

Fig. 6 Involvement in number of standards released over time for organisation types 
types have been involved in standards released during a varying number of the total 20 years of W3C standardisation (for organisation type from top to bottom in Fig. 6 for standards released during 18, 16, 19, 15, $16,11,14,9,4$, and 2 years, respectively) and with a varying amount of involvement and degree of continuity.

Figure 7 illustrates involvement in number of standards released over time for the top 15 countries. We note that only the top country (the United States) has been continuously involved in standards released since the beginning of W3C standardisation. Further, it can be observed that countries amongst the top 15 have been involved in standards released during a varying number of the total 20 years of W3C standardisation (for countries from top to bottom in Fig. 7 during $20,13,7,12,6,9,7,8,6,9,7,7,6,3$ and 4 years, respectively) and with a varying amount of involvement and degree of continuity.

In summary, it is evident that W3C standard development has taken place over a period of approximately 20 years with many standard development projects overlapping in time. A strong growth in number of projects has been experienced over time. Further, a standardisation organisation and the United States have been continuously involved in standards released since the beginning of W3C standardisation. Larger enterprises have been most extensively involved over time compared to other organisation types. Other organisations, organisation types, and countries have been involved in standards released during a varying number of the total 19 years of W3C standardisation. In these results it should be noted that involvement in development of a standard in many cases takes place over several years before the year for the release of the $\mathrm{W} 3 \mathrm{C}$ recommendation.

\subsection{Organisational involvement in different technologies}

Table 2 shows the top 5 technologies for the top 15 organisations that through editorship are involved in the largest number of standards (as ranked in Fig. 2). The table shows total number of technologies ("\# tec"), and a ranked list of technologies (sorted by number of standards involved in for each technology) for each organisation. The grey cells indicate technologies that cover the same (lowest) number of standards for an organisation amongst the top 5. An asterisk (*) in the rightmost column (at the fifth technology) indicates that there are one or more other technologies with the same number of standards below the top 5. Technologies have been (globally) ranked T1 through T89 (see Appendix) based on number of times an organisation has contributed through editorship to a standard that is mapped to the technology. For example, T1 represents "OWL Web Ontology Language" and has 71 organisational contributions to standards that belong to this technology. In Table 2 it can be observed that top organisations typically contribute to a diverse set of technologies, both highly ranked and technologies with a lower rank. For example O1, has amongst its top 5 technologies contributed to the highly ranked $\mathrm{T} 2$ and $\mathrm{T} 6$. The same organisation has also contributed to T16 which is of

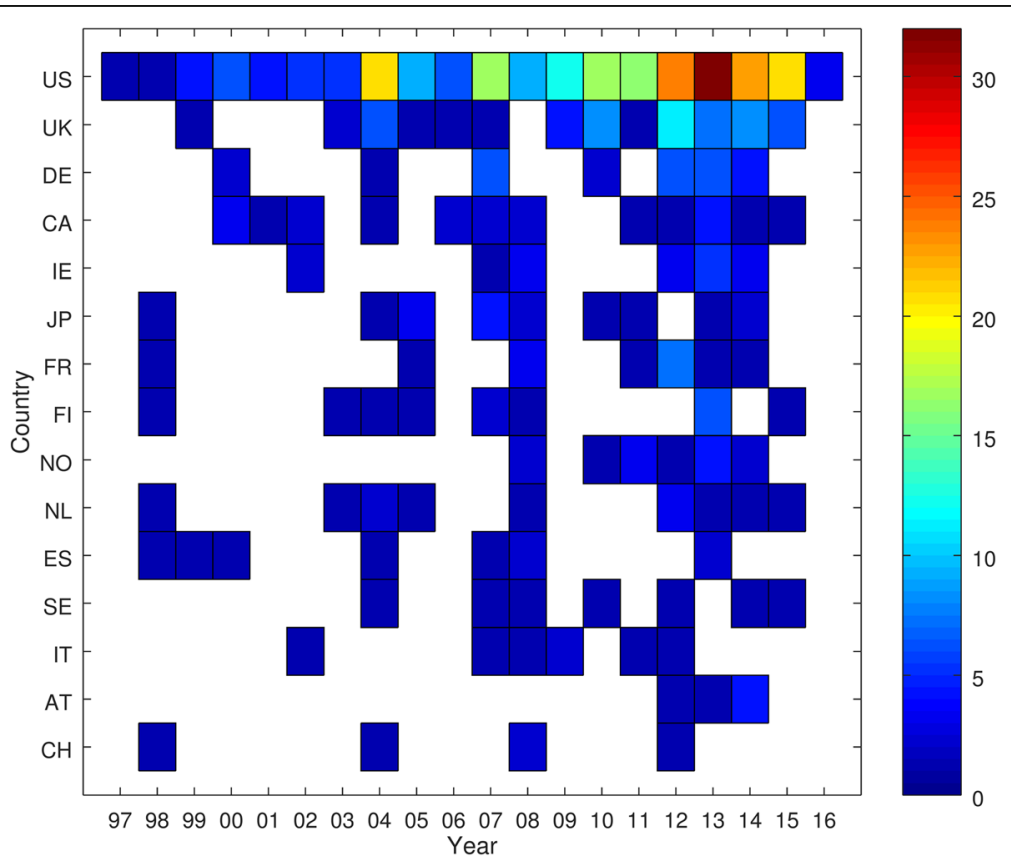

Fig. 7 Involvement in number of standards released over time for the top 15 countries 
Table 2 Top 5 technologies for the top 15 organisations

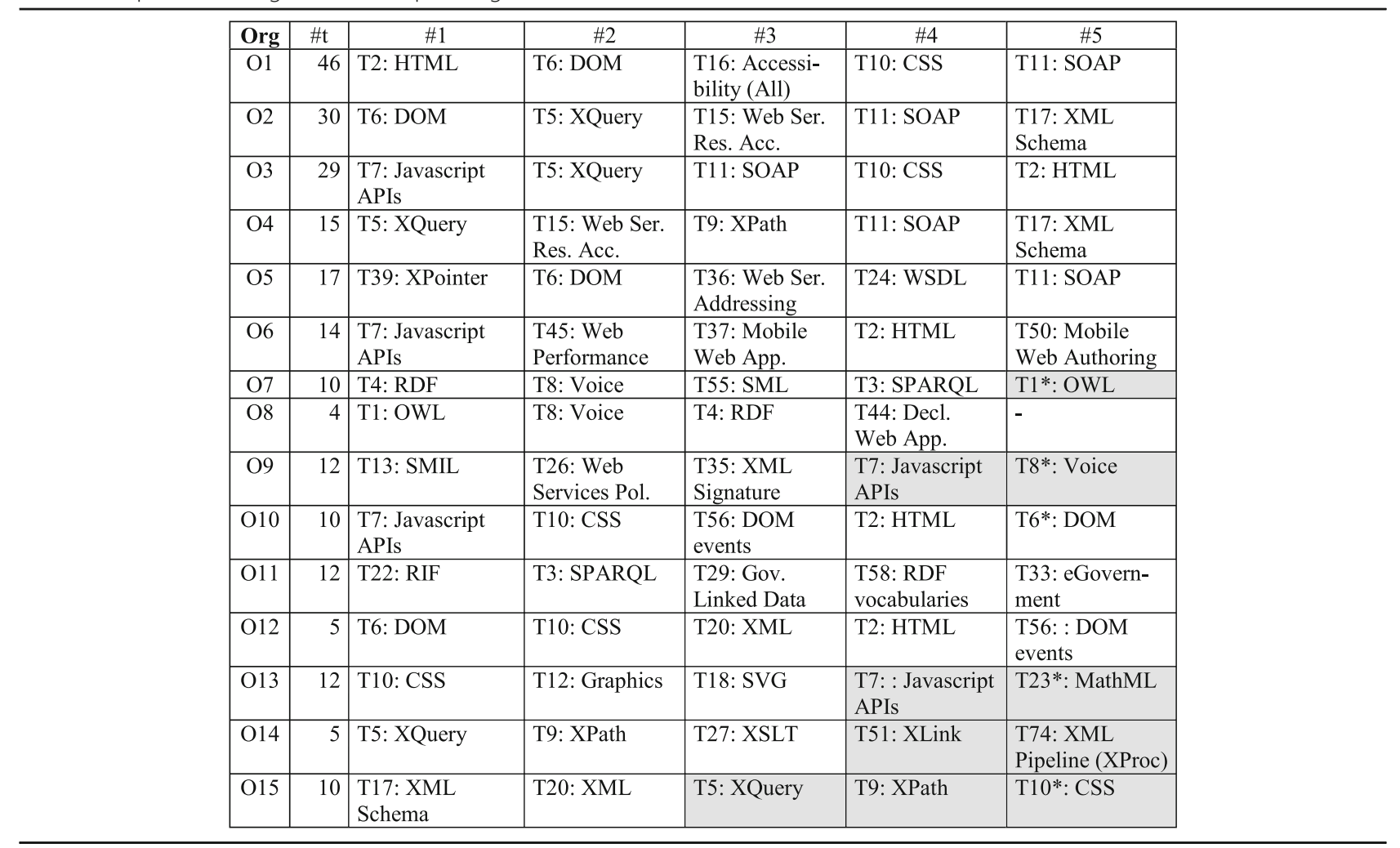

lower rank. We also note that three of the top 15 organisations $(\mathrm{O} 8, \mathrm{O} 12$, and $\mathrm{O} 14)$ seem more specialised as they have contributed to notably smaller sets of technologies (sized 4, 5, and 5, respectively), compared to other organisations in the top 15 .
In order to look deeper (beyond the top 5 list of technologies) into what technologies different organisations in the top 15 have in common when accounting for all technologies organisations contribute to, Table 3 illustrates different intersections of technologies for the top

Table 3 Intersection of technologies for top two through top 15 organisations

\begin{tabular}{|c|c|c|c|c|c|c|c|}
\hline$\overline{\mathrm{Tec}}$ & & TP2 & TP3 & TP4 & TP5 & TP6 & $\overline{T P 7-T P 15}$ \\
\hline $\mathrm{T1}$ & $\mathrm{OWL}$ & $x$ & & & & & \\
\hline $\mathrm{T} 2$ & HTML & $x$ & $x$ & & & & \\
\hline T3 & SPARQL & $x$ & & & & & \\
\hline T4 & RDF & $x$ & & & & & \\
\hline T6 & DOM & $x$ & $x$ & $x$ & $x$ & $x$ & \\
\hline T11 & SOAP & $x$ & $x$ & $x$ & $x$ & & \\
\hline T12 & Graphics & $x$ & $x$ & & & & \\
\hline T14 & Linked Data & $x$ & & & & & \\
\hline T16 & Accessibility (All) & $x$ & & & & & \\
\hline $\mathrm{T} 18$ & SVG & $x$ & $x$ & & & & \\
\hline T24 & WSDL & $x$ & & & & & \\
\hline T35 & XML Signature & $x$ & $x$ & & & & \\
\hline T38 & XHTML Modularization & $x$ & & & & & \\
\hline T48 & Accessible Rich Internet Applications & $x$ & & & & & \\
\hline T53 & XML Encryption & $x$ & & & & & \\
\hline T61 & PICS & $x$ & & & & & \\
\hline
\end{tabular}


two through 15 organisations. It can be observed that the top six organisations have all been involved in editorship in standards related to "DOM", and the top five organisations have also been involved in "SOAP". Top three organisations also have "HTML", "Graphics", "SVG", and "XML Signature", in common. We also note that the top two organisations have an additional 10 technologies (summing up to 16) in common.

When considering all organisations (not only the top 15), there are unique sets of technologies for three of the 234 organisations contributing to W3C through editorship. O2 (a LE) is alone involved in editorship for T84 ("XSL-FO") and T86 ("XForms"), O4 (a LE) is alone involved in T87 ("HTTP") and T89 ("Geospatial"), and a university (ranked as number 16 in terms of involvement in number of standards) is the only organisation that is editor for T88 ("PNG").

Table 4 shows the top 5 technologies for the 10 organisation types (as ranked in Fig. 3). It can be noted that larger enterprises contribute to technologies that are amongst the 7 most highly ranked technologies overall. We also observe that other organisation types contribute to a more diverse set of technologies, both highly ranked and technologies with a lower rank. For example, SME has amongst its top 5 technologies contributed to the highly ranked T2 and T4. The same organisation type has also in the top 5 list contributed to T26, which is of lower rank. We also note that organisation the types $\mathrm{H}$ and PBS have contributed to few technologies, which is natural since the organisation types have contributed to few standards.

Table 5 shows different intersections of technologies for the top two through top 10 (i.e. all) organisation types. It can be observed that all organisation types been involved in editorship in standards related to T3 ("SPARQL"), and the top eight organisation types have also been involved in T10 ("CSS"). Top seven organisations also have T2 ("HTML"), T4 ("RDF"), and T20 ("XML"), in common. We also note that the top six through top two organisations have a growing number of technologies in common $(12,18,22,26$, and 41 , respectively).

There are unique sets of technologies for two of the 10 organisation types contributing to W3C through editorship. Larger enterprises (LE) are alone involved in 12 of the 89 technologies: T15 ("Web Services Resource Access"), T36 ("Web Services Addressing"), T45 ("Web Performance"), T55 ("Service Modeling Language (SML)"), T56 ("DOM events"), T60 ("XML-binary Optimized Packaging"), T66 ("XKMS"), T67 ("Security for Web Applications"), T84 (“XSL-FO"), T86 ("XForms"), T87 ("HTTP”), and T89 ("Geospatial"). Universities (Uni) are alone involved in two technologies: T42 ("Provenance") and T88 ("PNG").

Table 6 shows the top 5 technologies for the top 15 countries involved in W3C standardisation through editorship (as ranked in Fig. 4). It can be observed that the United States (US) contribute to four of the five most highly ranked technologies in the top 5 list of technologies. We also observe that other countries contribute to a more diverse set of technologies, both highly ranked and technologies with a lower rank. For example Germany (DE), has amongst its top 5 technologies contributed to the highly ranked T1, and T3, and same country has also in the top 5 list contributed to the lower ranked T21 and T22. It is also worth to note that even for countries contributing to a relatively small number of standards (e.g. IT, AT, and $\mathrm{CH}$ ), the involvement is distributed over a diversified set of technologies.

Table 7 illustrates different intersections of technologies for the top two through top 15 countries. It can be observed that the top four countries have all been involved in

Table 4 Top 5 technologies for the 10 organisation types

\begin{tabular}{|c|c|c|c|c|c|c|}
\hline Type & $\# \mathrm{t}$ & $\# 1$ & $\# 2$ & $\# 3$ & $\# 4$ & $\# 5$ \\
\hline LE & 78 & $\begin{array}{l}\text { T7: Javascript } \\
\text { APIs }\end{array}$ & T1: OWL & T5: XQuery & T2: HTML & T6: DOM \\
\hline Uni & 48 & T1: OWL & T4: RDF & T3: SPARQL & $\begin{array}{l}\text { T16: Accessi- } \\
\text { bility (All) }\end{array}$ & T22: RIF \\
\hline SO & 46 & T2: HTML & T6: DOM & $\begin{array}{l}\text { T16: Accessi- } \\
\text { bility (All) }\end{array}$ & T10: CSS & T11: SOAP \\
\hline SME & 43 & T2: HTML & T8: Voice & T4: RDF & T6: DOM & T23: MathML \\
\hline $\mathrm{MiE}$ & 37 & T9: XPath & T5: XQuery & T27: XSLT & $\begin{array}{l}\text { T14: Linked } \\
\text { Data }\end{array}$ & T6: DOM \\
\hline RI & 27 & T1: OWL & T4: RDF & $\begin{array}{l}\text { T33: eGovern- } \\
\text { ment }\end{array}$ & $\begin{array}{l}\text { T14: Linked } \\
\text { Data }\end{array}$ & T40: POWDER \\
\hline NPO & 18 & T23: MathML & T3: SPARQL & T4: RDF & $\begin{array}{l}\text { T16: Accessi- } \\
\text { bility (All) }\end{array}$ & T30: RDFa \\
\hline other & 16 & T22: RIF & $\begin{array}{l}\text { T43: CSV on } \\
\text { the Web }\end{array}$ & $\begin{array}{l}\text { T17: XML } \\
\text { Schema }\end{array}$ & $\begin{array}{l}\text { T7: Javascript } \\
\text { APIs }\end{array}$ & T3*: SPARQL \\
\hline $\mathrm{H}$ & 3 & T3: SPARQL & T13: SMIL & T85: GRDDL & - & - \\
\hline PBS & 2 & T3: SPARQL & $\begin{array}{l}\text { T21: Media } \\
\text { Access }\end{array}$ & - & - & - \\
\hline
\end{tabular}


Table 5 Intersection of technologies for top two through top 10 organisation types

\begin{tabular}{|c|c|c|c|c|c|c|c|c|c|c|}
\hline Tec & & Tp2 & Tp3 & Tp4 & Tp5 & Tp6 & Tp7 & Tp8 & Tp9 & Tp10 \\
\hline $\mathrm{T} 1$ & $\mathrm{OWL}$ & $x$ & $x$ & & & & & & & \\
\hline $\mathrm{T} 2$ & HTML & $x$ & $x$ & $x$ & $x$ & $x$ & $x$ & & & \\
\hline T3 & SPARQL & $x$ & $x$ & $x$ & $x$ & $x$ & $x$ & $x$ & $x$ & $x$ \\
\hline T4 & $\mathrm{RDF}$ & $x$ & $x$ & $x$ & $x$ & $x$ & $x$ & & & \\
\hline T5 & XQuery & $x$ & & & & & & & & \\
\hline $\mathrm{T7}$ & Javascript APIs & $x$ & $x$ & $x$ & $x$ & $x$ & & & & \\
\hline T8 & Voice & $x$ & & & & & & & & \\
\hline T9 & XPath & $x$ & & & & & & & & \\
\hline T10 & CSS & $x$ & $x$ & $x$ & $x$ & $x$ & $x$ & $x$ & & \\
\hline $\mathrm{T} 12$ & Graphics & $x$ & $x$ & $x$ & $x$ & $x$ & & & & \\
\hline $\mathrm{T} 13$ & SMIL & $x$ & $x$ & & & & & & & \\
\hline T14 & Linked Data & $x$ & $x$ & $x$ & $x$ & $x$ & & & & \\
\hline T16 & Accessibility (All) & $x$ & $x$ & $x$ & $x$ & & & & & \\
\hline $\mathrm{T} 17$ & XML Schema & $x$ & $x$ & $x$ & $x$ & & & & & \\
\hline T18 & SVG & $x$ & & & & & & & & \\
\hline T19 & RDF Relationship to Other Formats & $x$ & $x$ & $x$ & $x$ & & & & & \\
\hline T20 & $\mathrm{XML}$ & $x$ & $x$ & $x$ & $x$ & $x$ & $x$ & & & \\
\hline $\mathrm{T} 21$ & Media Access & $x$ & & & & & & & & \\
\hline $\mathrm{T} 22$ & RIF Rule Interchange Format & $x$ & $x$ & $x$ & & & & & & \\
\hline T25 & Internationalization (All) & $x$ & $x$ & $x$ & $x$ & $x$ & & & & \\
\hline $\mathrm{T} 27$ & XSLT & $x$ & & & & & & & & \\
\hline T28 & SVG Tiny & $x$ & $x$ & $x$ & $x$ & & & & & \\
\hline T29 & Government Linked Data & $x$ & $x$ & $x$ & $x$ & $x$ & & & & \\
\hline T31 & Internationalization of XML & $x$ & $x$ & $x$ & $x$ & $x$ & & & & \\
\hline T32 & Internationalization of Web Architecture & $x$ & $x$ & $x$ & $x$ & $x$ & & & & \\
\hline T33 & eGovernment & $x$ & $x$ & $x$ & $x$ & X & & & & \\
\hline T35 & XML Signature & $x$ & $x$ & $x$ & & & & & & \\
\hline T38 & XHTML Modularization & $x$ & & & & & & & & \\
\hline $\mathrm{T} 40$ & POWDER & $x$ & & & & & & & & \\
\hline T41 & XML Design Techniques & $x$ & & & & & & & & \\
\hline T43 & CSV on the Web & $x$ & $x$ & $x$ & & & & & & \\
\hline T48 & Accessible Rich Internet Applications & $x$ & $x$ & & & & & & & \\
\hline T49 & XHTML For Mobile & $x$ & & & & & & & & \\
\hline T50 & Mobile Web Authoring & $x$ & $x$ & $x$ & $x$ & & & & & \\
\hline T54 & Efficient XML Interchange & $x$ & $x$ & $x$ & & & & & & \\
\hline T55 & Service Modeling Language & $x$ & & & & & & & & \\
\hline T57 & RDB2RDF & $x$ & $x$ & & & & & & & \\
\hline T68 & InkML & $x$ & & & & & & & & \\
\hline T69 & SKOS & $x$ & & & & & & & & \\
\hline T75 & Web Fonts & $x$ & & & & & & & & \\
\hline T79 & Best Practices for Authoring HTML & $x$ & & & & & & & & \\
\hline
\end{tabular}


Table 6 Top 5 technologies for the 10 organisation types

\begin{tabular}{|c|r|l|l|l|l|l|}
\hline Type & $\# t$ & \multicolumn{1}{|c|}{$\# 1$} & \multicolumn{1}{c|}{$\# 2$} & \multicolumn{1}{c|}{$\# 3$} & \multicolumn{1}{c|}{$\#$ \#4 } \\
\hline US & 85 & $\begin{array}{l}\text { T7: Javascript } \\
\text { APIs }\end{array}$ & T1: OWL & T2: HTML & T4: RDF & T3: SPARQL \\
\hline GB & 33 & T1: OWL & T9: XPath & T5: XQuery & T27: XSLT & T23: MathML \\
\hline DE & 27 & T1: OWL & T6: DOM & T3: SPARQL & $\begin{array}{l}\text { T21: Media } \\
\text { Access }\end{array}$ & T22*: RIF \\
\hline CA & 14 & T22: RIF & T6: DOM & T20: XML & $\begin{array}{l}\text { T16: Accessi- } \\
\text { bility (All) }\end{array}$ & T65: ATAG \\
\hline IE & 22 & $\begin{array}{l}\text { T14: Linked } \\
\text { Data }\end{array}$ & $\begin{array}{l}\text { T33: eGovern- } \\
\text { ment }\end{array}$ & T4: RDF & $\begin{array}{l}\text { T29: Govern- } \\
\text { ment Link. Dat. }\end{array}$ & T1*: OWL \\
\hline JP & 12 & T13: SMIL & T11: SOAP & $\begin{array}{l}\text { T54: Efficient } \\
\text { XML Interch. }\end{array}$ & T24: WSDL & T12: Graphics \\
\hline FR & 12 & T13: SMIL & $\begin{array}{l}\text { T21: Media } \\
\text { Access }\end{array}$ & T34: Widgets & T10: CSS & T1: OWL \\
\hline FI & 13 & T13: SMIL & $\begin{array}{l}\text { T26: Web } \\
\text { Services Policy }\end{array}$ & $\begin{array}{l}\text { T35: XML } \\
\text { Signature }\end{array}$ & T3: SPARQL & $\begin{array}{l}\text { T7*: Javascript } \\
\text { APIs }\end{array}$ \\
\hline NO & 13 & T10: CSS & T12: Graphics & T18: SVG & $\begin{array}{l}\text { T7: Javascript } \\
\text { APIs }\end{array}$ & T3*: SPARQL \\
\hline NL & 10 & T1: OWL & T13: SMIL & T2: HTML & T3: SPARQL & T4*: RDF \\
\hline ES & 7 & T3: SPARQL & T13: SMIL & T6: DOM & T9: XPath & T12*: Graphics \\
\hline SE & 11 & T2: HTML & T8: Voice & T11: SOAP & T12: Graphics & T18*: SVG \\
\hline IT & 4 & T8: Voice & T40: POWDER & T1: OWL & T73: P3P & T21: Media \\
\hline AT & 7 & T4: RDF & $\begin{array}{l}\text { T7: Javascript } \\
\text { APIs }\end{array}$ & $\begin{array}{l}\text { T14: Linked } \\
\text { Data }\end{array}$ & $\begin{array}{l}\text { T1* OWL } \\
\text { Access }\end{array}$ \\
\hline CH & 6 & T13: SMIL & T12: Graphics & T18: SVG & $\begin{array}{l}\text { T21: Media } \\
\text { Access }\end{array}$ & $\begin{array}{l}\text { T28*: SVG } \\
\text { Tiny }\end{array}$ \\
\hline
\end{tabular}

T12 ("Graphics"). The top three have the top five technologies (T1 (“OWL Web Ontology Language"), T2 ("HTML"), T3 ("SPARQL"), T4 ("RDF"), and T5 ("XQuery")), and 10 additional technologies, in common. We also note that the top two countries have 30 technologies in common.

When considering all countries (not only the top $15)$, there are unique sets of technologies for two of the 26 countries contributing to W3C through editorship. The United States is the only country involved in 17 of the 89 technologies: T15 ("Web Services Resource Access"), T39 ("XPointer"), T45 ("Web Performance"), T51 ("XLink"), T55 ("Service Modeling Language (SML)"), T61 (“PICS"), T66 (“XKMS”), T71 ("Quality Assurance (QA) Framework"), T77 (“User Agent Accessibility Guidelines (UAAG)"), T80 ("Security for User Agents"), T81 ("Web Architecture"), T83 ("Timed Text"), T84 (“XSL-FO"), T85 (“GRDDL"), T86 (“XForms"), T87 ("HTTP”), and T89 ("Geospatial"). Great Britain is the only country involved in the two standards T69 ("SKOS") and T88 ("PNG").

In summary, results at organisation level show that top contributing organisations typically contribute to a diverse set of $\mathrm{W} 3 \mathrm{C}$ technologies, and there are several technologies that these organisations have in common. Further, there are unique sets of technologies for three organisations (two larger enterprises and one university). The fact the some technologies are not only dominated, but driven alone (at least at editor level) by certain larger enterprises may be considered problematic since it has been claimed that some companies "aim to control the strategy of" a standardisation organisation [23]. From results at organisation type level it is evident that larger enterprises dominate by contributing primarily to the most highly ranked (in terms of organisational contributions) technologies. Other organisation types contribute to a more diversified set of technologies (where some have lower rank and are therefore in a manner more specialised). Results also show that there are a number of common technologies for the majority of the organisation types. Further, there are unique sets of technologies for two of the organisation types. Larger enterprises are alone involved in editorship in standards for 12 of 89 technologies, and universities are alone editors in standards for two technologies. The domination by larger enterprises may be problematic, as mentioned earlier. Results at country level show that the United States dominate by contributing primarily to the most highly ranked technologies. Other top contributing countries are involved in a more diversified set of technologies. Results also show that there are a number of common technologies for the top three contributing countries. Further, there are unique sets of technologies for two of the countries. The United States are alone involved in editorship in standards for 17 of 89 technologies, and Great Britain are alone editors in standards for two technologies. The early establishment of the W3C Foundation at MIT in 1994 with a US based headquarter for W3C, and the fact that a large proportion (51\%) of W3C members 
Table 7 Intersection of technologies for top two through top

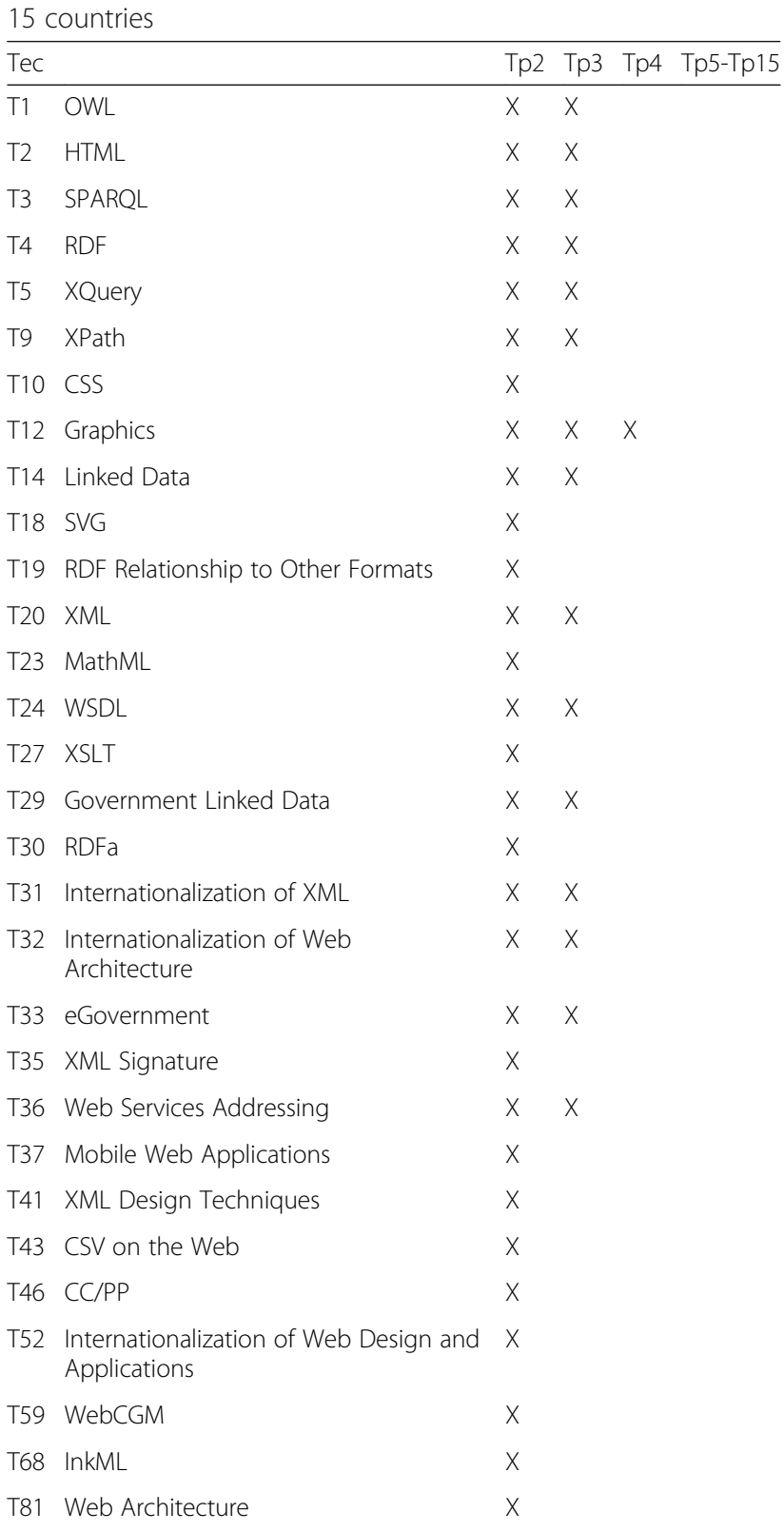

were US based as early as 1997 [20], may contribute to explain the US dominance in terms of editorship.

\subsection{Organisational involvement in relation to standard development time}

At time of data collection, there are 265 W3C standards which have reached recommendation status. Figure 8 illustrates the distribution of development time (defined as the difference between date for recommendation and date for first published version, which is typically a working draft). The minimum and maximum development time is 47 and 5801 days, respectively. Average and median for development time is 1542 , and 1246 days, respectively. There is a standard deviation of 1195 days.

Figure 9 illustrates the earliest and most recent date for the 265 standards sorted by development time. Based on intervals in Fig. 9, Fig. 10 shows the number of standards concurrently in development over time. Overall, from Fig. 9, we note that there is a complex development pattern over time with many standard development projects overlapping in time. Further, Fig. 10 indicates an increase in number of standards being developed over time until approximately day 2500 , from where the number of concurrent standards remains around 70 in number until approximately day 4400 where the number of concurrent standards increases again. We acknowledge that only standards that have reached recommendation status are part of the analysis, which contributes to explain the drop in number of concurrent standards from approximately day 6000 and onwards.

Table 8 shows the top 15 W3C standards (and associated technologies) in terms of short development time (where "Time" is development time (in Days), "\# org" is the number of organisations that are editors). For example, we note that the top four standards are part of technology T6 ("DOM") and the next two are part of T2 ("HTML"). There are also standards that are part of lower ranked technologies (e.g. "GRDDL Test Cases" - part of T85, and "Device Description Repository Simple API" part of T63) that are amongst the top 15 W3C standards in terms of short development time.

Table 9 shows the top 15 W3C standards (and associated technologies) in terms of long development time. We note that several of these standards are part of highly ranked technologies, such as T4 ("RDF") with two standards, and T10 ("CSS") with seven standards. There are also examples of standards that are part of lower ranked technologies amongst the top $15 \mathrm{~W} 3 \mathrm{C}$ standards in terms of long development time, e.g. four standards related to T61 ("PICS").

By just studying Tables 8 and 9 , it is difficult to establish whether there is a connection between number of organisations and the development time since number of organisations varies considerably in Table 8 (from 1 to 9) and 9 (from 0 to 5). Therefore a correlation calculation involving all 265 W3C standards was performed between number of organisations (at editor level) and the development time. It was found that there is very low correlation (Pearson correlation of 0.06 ), suggesting that there is no relation between number of organisations and development time.

Figure 11 shows a standard box plot illustrating standard development time statistics for the standards that different organisation types contribute to (where lower and upper fences show minimum and maximum values, the bottom and top whiskers show lower and upper quartile values, the horisontal line in the box shows median values, 


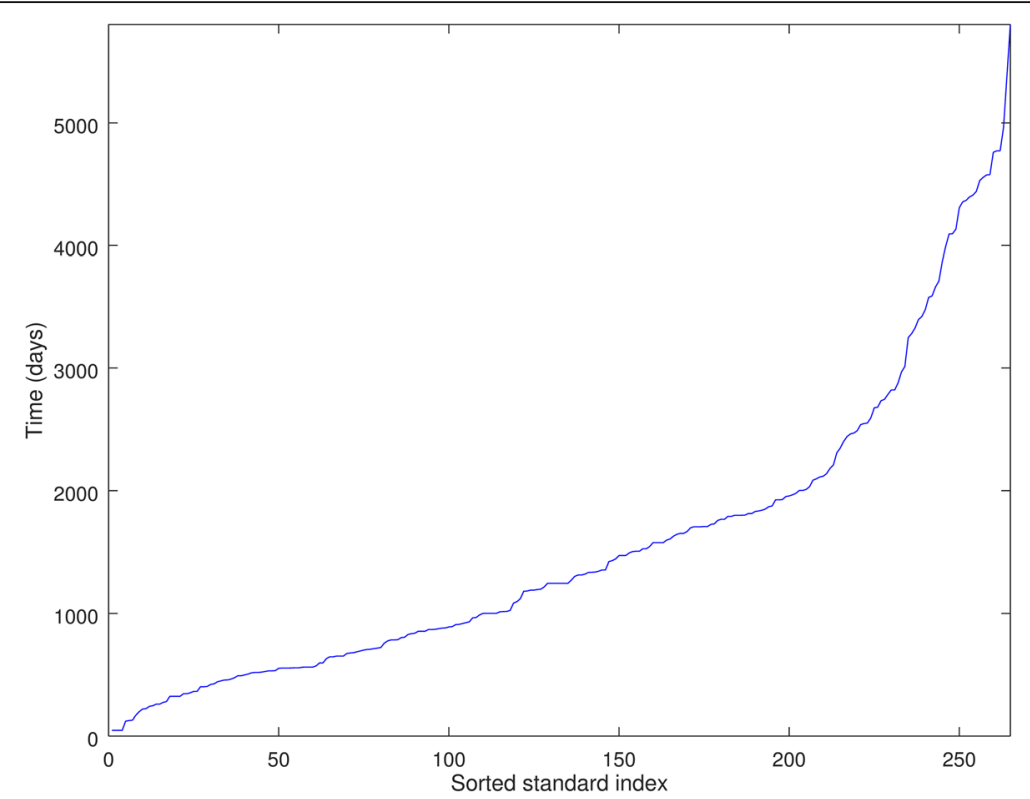

Fig. 8 Distribution of development time for W3C standards

plus signs show outliers between 1.5 and 3 times the upper quartile value, and rings show outliers outside 3 times the upper quartile value). It can be observed that, on average, standards involving research institutes (RI) have the shortest development time (if $\mathrm{H}$ and PBS are excluded due to low number of standards), and standards involving universities (Uni) have the longest development time. Further, it can be observed that for each organisation type there is a wide variation in development time. For example, development time for standards involving larger enterprises (LE) vary between 47 and 5801 days with quite a large variability. In comparison, research institutes (RI) are involved in standards exhibiting a tighter development time interval (between 218 and 4555 days) with considerably lower variability.

By just studying Fig. 11, it is hard to establish whether there is a tendency of longer (or shorter) development time in standards that have editor participation from a certain organisation type when comparing with a another organisation type since there are

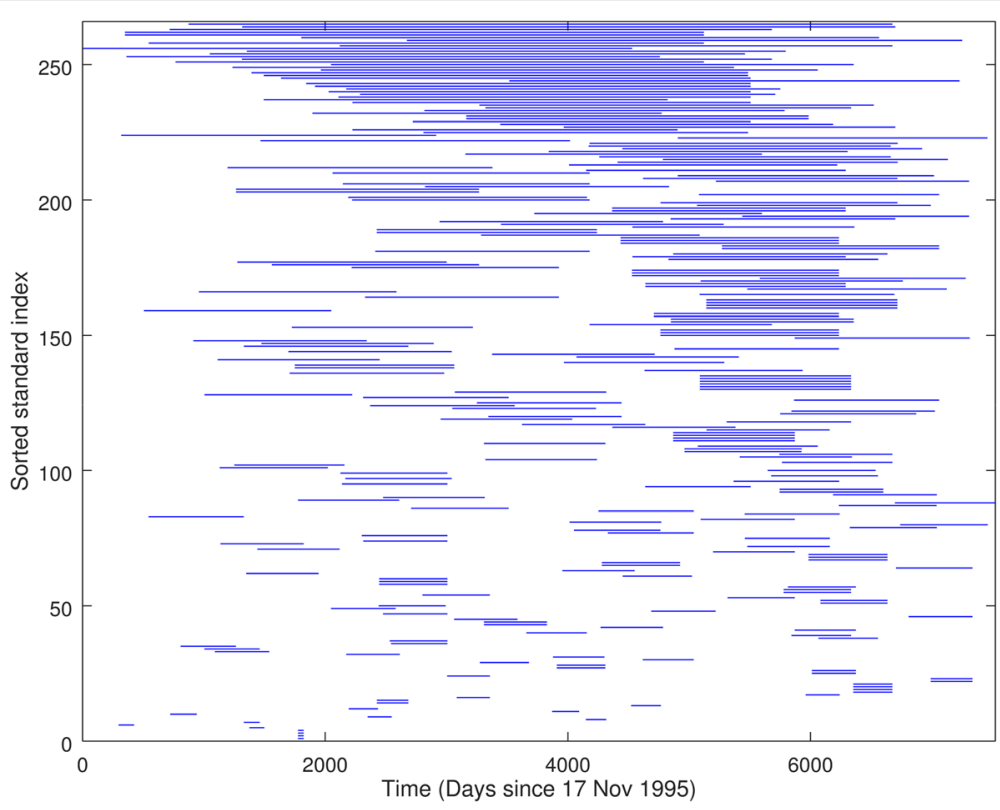

Fig. 9 Development time intervals for W3C standards 


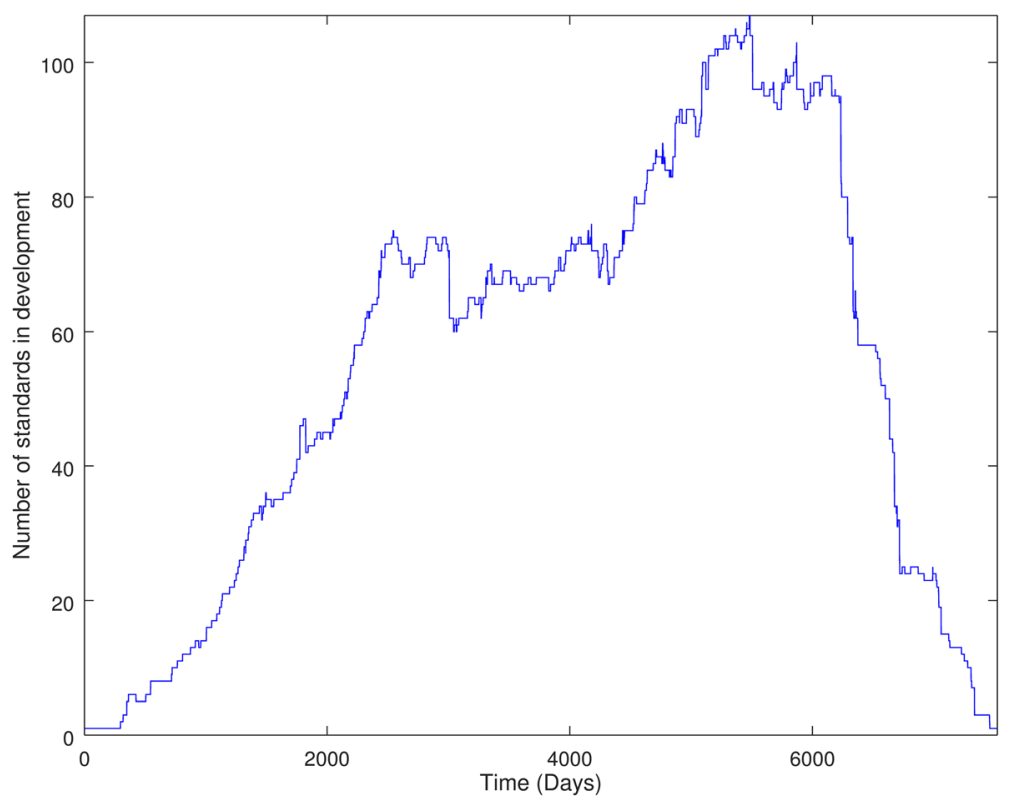

Fig. 10 Number of standards in development over time

overlapping value intervals for different organisation types. Therefore, based on statistics illustrated in Fig. 11, Table 10 shows the results from a statistical significance test for different comparisons of organisation types by use of the non-parametric Mann-Whitney one-sided utest $^{16}$ and the one-sided alternative null hypothesis $\operatorname{PROB}(\mathrm{X}>\mathrm{Y})>1 / 2$, where $\mathrm{X}$ and $\mathrm{Y}$ are the samples. Hence, the hypothesis for each test is that development time for standards involving one specific organisation type has a tendency to be longer than development time for standards involving a different organisation type. In Table 10, cells containing symbols "> or "<" show comparisons that are statistically significant at the 95\% level. A symbol " $N$ " illustrates that the results from the comparison is not significant. In the comparisons, PBS has been excluded since only two standard involvements is insufficient for a reliable Mann-Whitney utest. From the results, it can be noted that there are significant differences in development time for a number of comparisons. For example, it can be observed that there is a tendency for longer development times for the set of standards involving larger enterprises (LE),

Table 8 Top 15 W3C standards in terms of short development time

\begin{tabular}{lllll}
\hline & Time & $\#$ org & Standard & Technology \\
\hline$\# 1$ & 47 & 1 & Document Object Model (DOM) Level 2 Events Specification & T6: DOM, T56: DOM events \\
$\# 2$ & 47 & 3 & Document Object Model (DOM) Level 2 Style Specification & T6: DOM \\
$\# 3$ & 47 & 6 & Document Object Model (DOM) Level 2 Traversal and Range Specification & T6: DOM \\
$\# 4$ & 47 & 3 & Document Object Model (DOM) Level 2 Views Specification & T6: DOM \\
$\# 5$ & 122 & 1 & HTML 4.01 Specification & T2: HTML \\
$\# 6$ & 127 & 1 & HTML 3.2 Reference Specification & T2: HTML \\
$\# 7$ & 130 & 1 & XSL Transformations (XSLT) Version 1.0 & T27: XSLT \\
$\# 8$ & 167 & 1 & GRDDL Test Cases & T85: GRDDL \\
$\# 9$ & 197 & 3 & XML-Signature XPath Filter 2.0 & T35: XML Signature \\
$\# 10$ & 218 & 9 & Synchronized Multimedia Integration Language (SMIL) 1.0 Specification & T13: SMIL \\
$\# 11$ & 221 & 3 & WebCGM 2.0 & T12: Graphics, T59: WebCGM \\
$\# 12$ & 240 & 3 & Exclusive XML Canonicalization Version 1.0 & T62: XML Canonicalization \\
$\# 13$ & 245 & 4 & Device Description Repository Simple API & T63: Device Description Repository \\
$\# 14$ & 258 & 3 & XPointer Framework & T39: XPointer \\
$\# 15$ & 258 & 4 & XPointer xmlns & T39: XPointer
\end{tabular}


Table 9 Top 15 W3C standards in terms of long development time

\begin{tabular}{|c|c|c|c|c|}
\hline & Time & \# org & Standard & Technology \\
\hline$\# 1$ & 5801 & 2 & RDF Schema 1.1 & T4: RDF \\
\hline \#2 & 5382 & 3 & CSS Namespaces Module Level 3 & T10: CSS \\
\hline \#3 & 4963 & 5 & Cascading Style Sheets Level 2 Revision 1 (CSS 2.1) Specification & T10: CSS \\
\hline \#4 & 4772 & 1 & $\begin{array}{l}\text { PICS } 1.1 \text { Rating Services and Rating Systems - and Their Machine } \\
\text { Readable Descriptions }\end{array}$ & T61: PICS \\
\hline \#5 & 4772 & 1 & $\begin{array}{l}\text { PICS } 1.1 \text { Label Distribution - Label Syntax and Communication } \\
\text { Protocols }\end{array}$ & T61: PICS \\
\hline$\# 6$ & 4761 & 4 & CSS Style Attributes & T2: HTML, T10: CSS \\
\hline \#7 & 4577 & 2 & Authoring Tool Accessibility Guidelines (ATAG) 2.0 & $\begin{array}{l}\text { T16: Accessibility, T65: Authoring Tool Accessibility } \\
\text { Guidelines (ATAG) }\end{array}$ \\
\hline \#8 & 4575 & 1 & PICS Signed Labels (DSig) 1.0 Specification & T61: PICS \\
\hline \#9 & 4555 & 3 & RDF 1.1 XML Syntax & T4: RDF \\
\hline \#10 & 4529 & $0^{\mathrm{a}}$ & Cascading Style Sheets (CSS1) Level 1 Specification & T10: CSS \\
\hline$\# 11$ & 4440 & 5 & Selectors Level 3 & T10: CSS \\
\hline \#12 & 4410 & 3 & Associating Style Sheets with XML documents 1.0 (Second Edition) & T10: CSS, T72: Stylesheets in XML \\
\hline$\# 13$ & 4395 & 5 & Extensible Markup Language (XML) 1.0 (Fifth Edition) & T20: XML \\
\hline \#14 & 4367 & 4 & CSS Color Module Level 3 & T10: CSS \\
\hline \#15 & 4355 & 1 & PICSRules 1.1 Specification & T61: PICS \\
\hline
\end{tabular}

${ }^{\mathrm{a}}$ No organisation has been declared as editor for this standard

and also for the set involving universities (Uni) compared to the sets of standards involving research institutes (RI), non-profit organisations (NPO) and hospitals $(\mathrm{H})$. Interestingly, there are no significant results from any comparison involving $\mathrm{SME}$ and $\mathrm{MiE}$, the other two commercial organisation types (apart from LE).

Similar to Fig. 11 in the case of organisation types, Fig. 12 shows a box plot illustrating standard development time statistics for the top 15 countries. It can be observed that, on average, standards involving Spain have the shortest development time, and standards involving Norway have the longest development time. Further, we note that for each organisation type there is a wide variation in development time. For example, development time for standards involving the United States (US) varies between 47 and 5801 days with quite a large variability. In

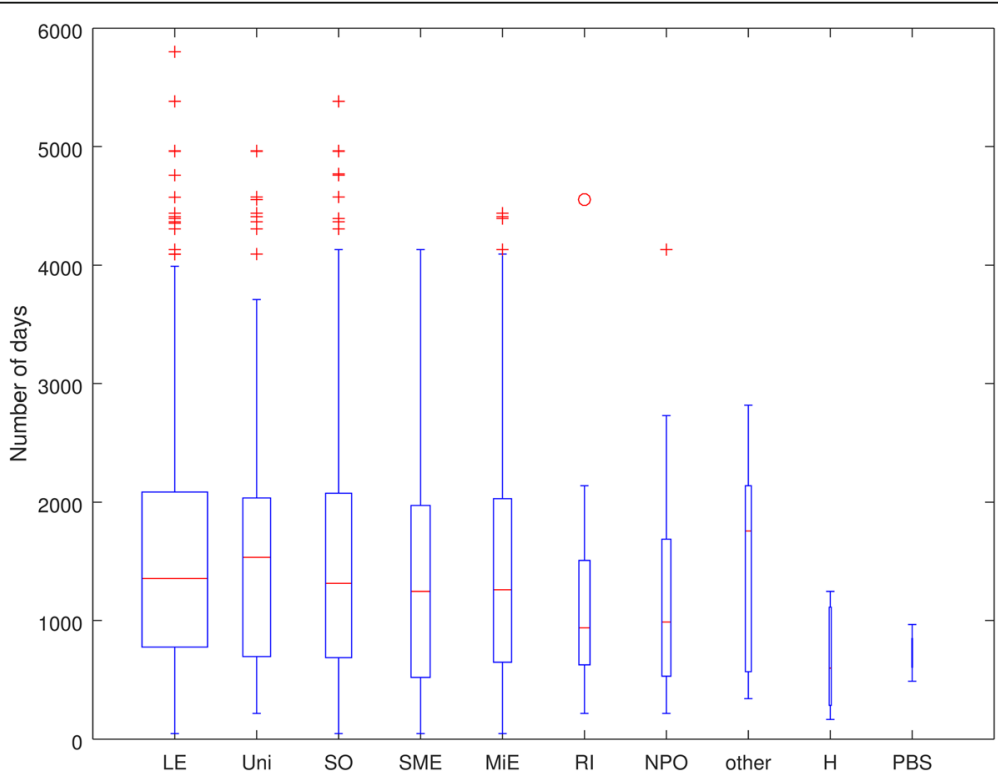

Fig. 11 Box plot illustrating development time statistics for organisation types 
Table 10 Statistical significance for comparisons of development time for organisation types

\begin{tabular}{|c|c|c|c|c|c|c|c|c|c|c|}
\hline & LE & Uni & $\mathrm{SO}$ & SME & MiE & $\mathrm{Rl}$ & NPO & other & $\mathrm{H}$ & PBS \\
\hline LE & & $\mathrm{N}$ & $N$ & $\mathrm{~N}$ & $N$ & $>$ & $>$ & $\mathrm{N}$ & $>$ & \\
\hline Uni & & & $N$ & $\mathrm{~N}$ & $\mathrm{~N}$ & $>$ & $>$ & $N$ & $>$ & \\
\hline SO & & & & $\mathrm{N}$ & $N$ & $>$ & $\mathrm{N}$ & $\mathrm{N}$ & $>$ & \\
\hline SME & & & & & $N$ & $\mathrm{~N}$ & $\mathrm{~N}$ & $\mathrm{~N}$ & $>$ & \\
\hline $\mathrm{MiE}$ & & & & & & $\mathrm{N}$ & $\mathrm{N}$ & $N$ & $>$ & \\
\hline $\mathrm{Rl}$ & & & & & & & $\mathrm{N}$ & $<$ & N & \\
\hline NPO & & & & & & & & $N$ & N & \\
\hline other & & & & & & & & & $>$ & \\
\hline $\mathrm{H}$ & & & & & & & & & & \\
\hline PBS & & & & & & & & & & \\
\hline
\end{tabular}

comparison, Ireland (IE) is involved in standards exhibiting a tighter development time interval (between 197 and 2139 days) with considerably lower variability.

In order to establish tendency of longer (or shorter) development time in standards that have editor participation from a certain country when comparing with a different country, Table 11 shows the results from a statistical significance test (based on statistics illustrated in Fig. 12), for different comparisons of countries by use of the MannWhitney test. From the results, it can be observed that there are significant differences in development time for a number of comparisons. For example, we note that there is a tendency for both shorter and longer development time for the set of standards involving the United States (US) compared to the sets of standards involving other countries (shorter development time for comparisons with
$\mathrm{GB}, \mathrm{NO}$, and SE; longer development time for comparisons with IE and ES). We also note a tendency for longer development time for standards that feature involvement from Norway (NO) for 12 out of 15 comparisons involving the country.

In summary, it is clear that development time spans from a couple of months to 15 years for different standards. There are both standards from highly ranked technologies and technologies with lower rank amongst standards with short and long development time. It was also shown that there is no connection between number of organisations in the editorial board and the development time. At organisation type level, results suggest that standards involving research institutes have the shortest development time on average (if excluding the two types hospital and public broadcasting service due to low level of standard involvement), and standards involving universities have the longest development time. In fact, when comparing development time between different organisation types, results show statistically significant differences for a number of comparisons. For example, there is a tendency for longer development times for larger enterprises and universities when comparing with research institutes, non-profit organisations, and hospitals. At country level, results suggest that standards involving Spain have the shortest development time on average and standards involving Norway have the longest development time. In fact, when comparing development time between different countries, results show statistically significant differences for a number of comparisons. For example, there is a tendency for both shorter and longer development times for standards involving the United States (US) compared to

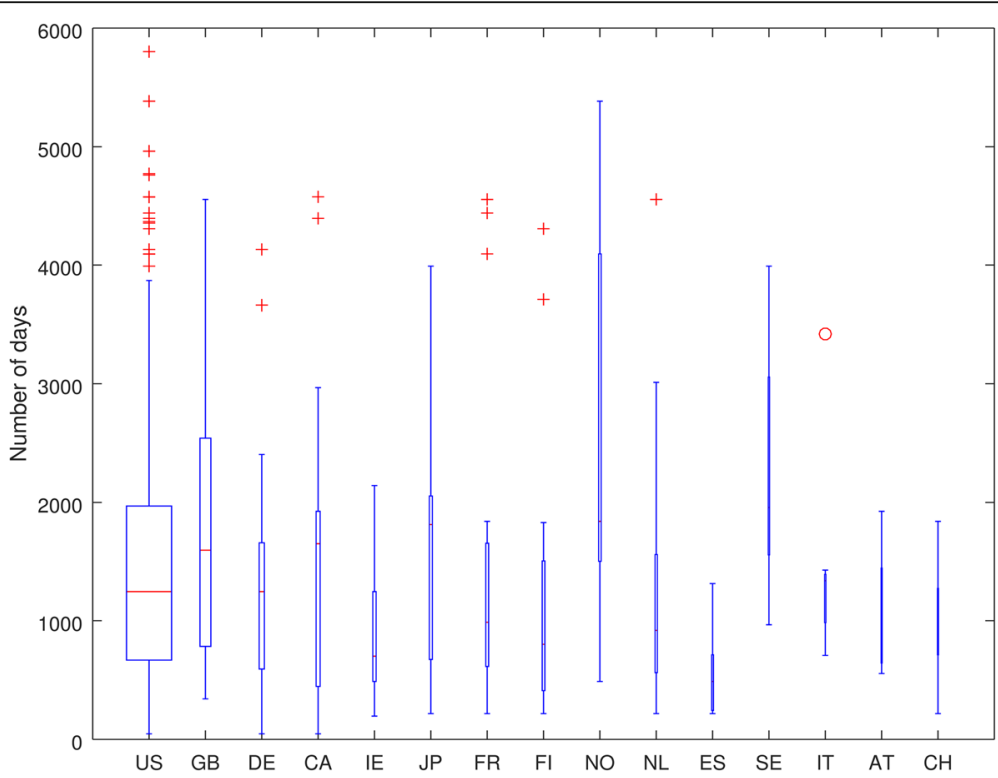

Fig. 12 Box plot illustrating development time statistics for countries 
Table 11 Statistical significance for comparisons of development time for countries

\begin{tabular}{|c|c|c|c|c|c|c|c|c|c|c|c|c|c|c|c|}
\hline & US & GB & $\mathrm{DE}$ & CA & $\mathrm{IE}$ & $J P$ & FR & $\mathrm{FI}$ & $\mathrm{NO}$ & $\mathrm{NL}$ & ES & SE & $\mathrm{IT}$ & AT & $\mathrm{CH}$ \\
\hline US & & $<$ & $N$ & $N$ & $>$ & $N$ & $\mathrm{~N}$ & $\mathrm{~N}$ & $<$ & $N$ & $>$ & $<$ & $N$ & $N$ & $N$ \\
\hline GB & & & $>$ & $N$ & $>$ & $\mathrm{N}$ & $\mathrm{N}$ & $>$ & $<$ & $N$ & $>$ & $N$ & $N$ & $\mathrm{~N}$ & $N$ \\
\hline$D E$ & & & & $N$ & $>$ & $N$ & $\mathrm{~N}$ & $\mathrm{~N}$ & $<$ & $\mathrm{N}$ & $>$ & $<$ & $N$ & $N$ & $N$ \\
\hline$C A$ & & & & & $N$ & $\mathrm{~N}$ & $\mathrm{~N}$ & $\mathrm{~N}$ & $<$ & $\mathrm{N}$ & $>$ & $N$ & $N$ & $N$ & $N$ \\
\hline IE & & & & & & $<$ & $\mathrm{N}$ & $\mathrm{N}$ & $<$ & $\mathrm{N}$ & $N$ & $<$ & $<$ & $N$ & $N$ \\
\hline$J P$ & & & & & & & N & $N$ & $N$ & $\mathrm{~N}$ & $>$ & $N$ & $N$ & $N$ & $N$ \\
\hline$F R$ & & & & & & & & $\mathrm{~N}$ & $<$ & $\mathrm{N}$ & $>$ & $N$ & $N$ & $N$ & $N$ \\
\hline $\mathrm{Fl}$ & & & & & & & & & $<$ & $\mathrm{N}$ & $N$ & $<$ & $N$ & $N$ & $N$ \\
\hline $\mathrm{NO}$ & & & & & & & & & & $>$ & $>$ & $N$ & $>$ & $>$ & $>$ \\
\hline $\mathrm{NL}$ & & & & & & & & & & & $>$ & $<$ & $N$ & $N$ & $N$ \\
\hline ES & & & & & & & & & & & & $<$ & $<$ & $<$ & $N$ \\
\hline SE & & & & & & & & & & & & & $N$ & $>$ & $>$ \\
\hline $\mathrm{IT}$ & & & & & & & & & & & & & & $N$ & $N$ \\
\hline AT & & & & & & & & & & & & & & & $N$ \\
\hline $\mathrm{CH}$ & & & & & & & & & & & & & & & \\
\hline
\end{tabular}

standards involving other countries (shorter development time when comparing with Great Britain, Norway, and Sweden; longer development time when comparing with Ireland and Spain).

\subsection{Organisational collaboration in W3C standardisation}

Figure 13 shows a social network representing W3C collaboration at organisational level (where a node represents an organisation and an edge represents collaboration through editorship for two organisations). There are 1211 edges $^{17}$ between 229 different

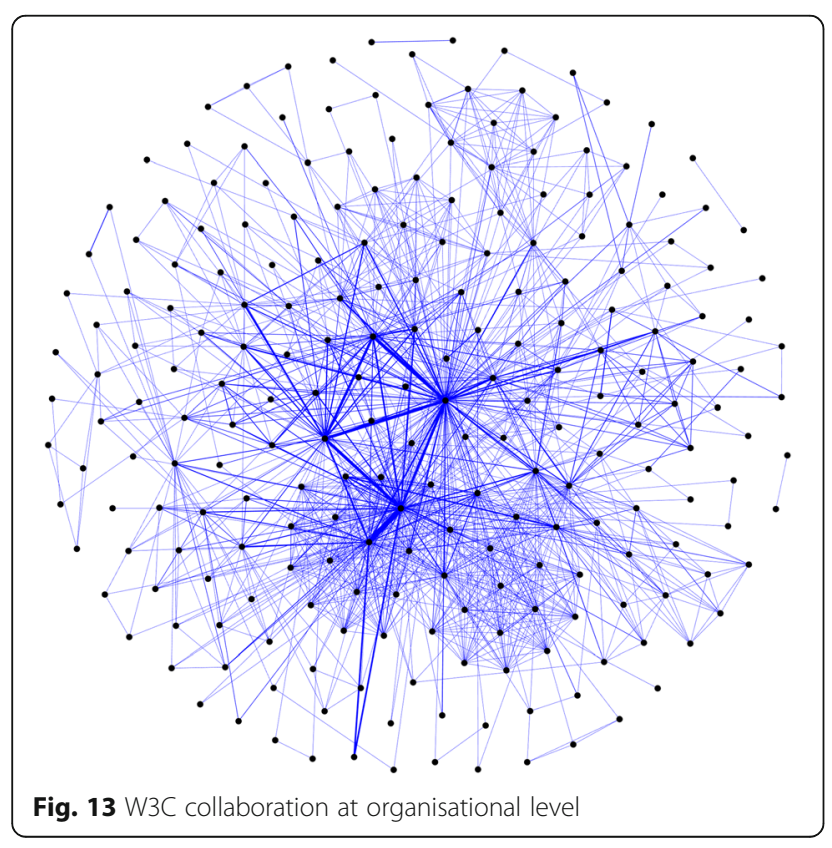

$\operatorname{organisations}^{18}$, which reflects the degree of diversity in collaboration overall. The degree $d$ of a node represents number of other organisations an organisation has collaborated with. The weight $w$ of an edge represents number of standards that two organisations (represented by the connected nodes) have collaborated in through editorship. The weighted degree $w d$ represents the sum of weights for edges connected to a node. The top 15 organisations in terms of collaboration (measured by weighted degree) are (in descending order) a SO ( $w d=267, d=133$ ), a LE (wd $=211, d=98)$, a LE ( $w d=133, d=48)$, a LE (wd $=132, \mathrm{~d}=69)$, a $\operatorname{LE}(\mathrm{wd}=102, \mathrm{wd}=47)$, a $\operatorname{LE}(\mathrm{wd}=$ $74, \mathrm{~d}=52$ ), a RI (wd $=62, \mathrm{~d}=44)$, a $\mathrm{LE}(\mathrm{wd}=60, \mathrm{~d}=$ 30), a Uni ( $w d=52, d=40)$, a Uni ( $w d=52, d=37)$, a LE (wd $=46, d=27)$, a RI ( $w d=42, d=29)$, a Uni ( $w d=42, d=24)$, a LE ( $w d=42, d=19)$, and a $L E$ ( $w d=39, d=27)$. The top five pairs of organisations collaborating most extensively are a LE and another LE $(\mathrm{w}=22)$ followed by a LE and a SO $(\mathrm{w}=14)$, a $\operatorname{LE}$ and another $\operatorname{LE}(\mathrm{w}=13)$, a SO and a $\operatorname{LE}(\mathrm{w}=13)$, and $a$ SO and a $\operatorname{LE~}(w=11)$. The remaining 1206 edges have a weight of 8 or less. In fact, $78 \%$ (941) of all edges have a weight of one, which means that such organisational collaboration has only taken place for one single standard (Fig. 13).

A social network representing W3C collaboration at organisation type level is shown in Fig. 14 (where a node represents an organisation type and an edge represents collaboration through editorship for two organisation types). There are in total 40 edges $^{19}$ between the ten different organisation types, which indicates a

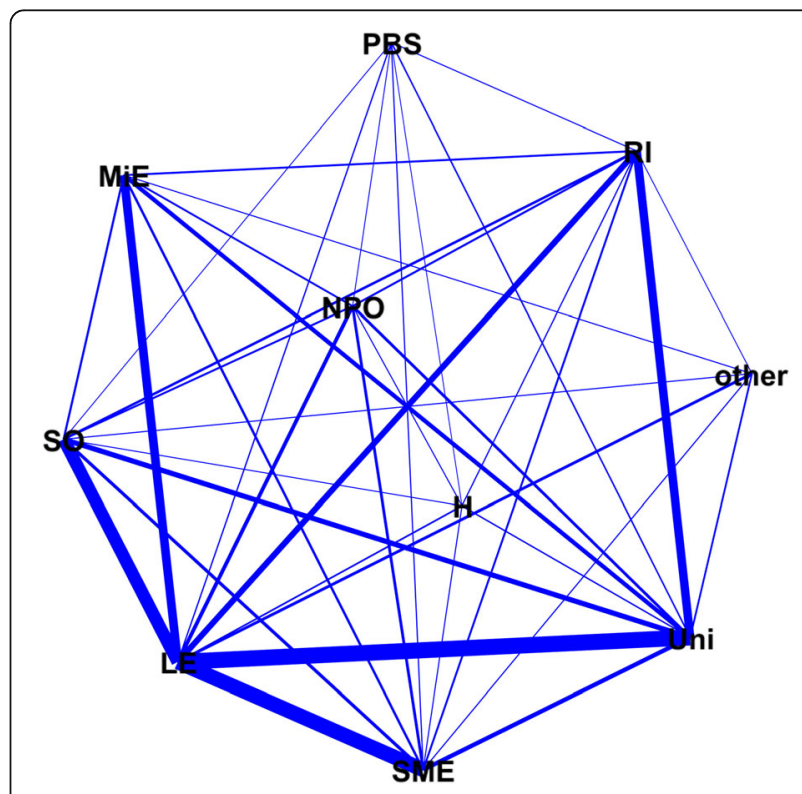

Fig. 14 W3C collaboration at organisation type level 
diversified collaboration overall at this level. The degree $d$ of a node represents number of other organisation types an organisation type has been associated with during organisational collaboration through editorship. The weight $w$ of an edge represents number of standards that organisations of two organisation types (represented by the connected nodes) have collaborated in through editorship. The weighted degree $w d$ represents the sum of weights for edges connected to a node. The rank order of the 10 organisation types in terms of collaboration (measured by weighted degree) are (in descending order) LE ( $w d=677, d=9)$, Uni ( $w d=435, d$ =9), SME ( wd =294, d =9), SO ( wd =267, d=9), RI $(w d=218, d=9), \operatorname{MiE}(w d=192, d=7), \quad N P O \quad(w d=$ $129, d=8)$, other $(w d=51, d=6), H(w d=37, d=7)$, and PBS ( $w d=30, d=7$ ). The top five pairs of organisation types collaborating most extensively are LE and Uni $(w=169)$ followed by LE and SME ( $w=156)$, LE and SO ( $w=131), \mathrm{LE}$ and MiE ( $\mathrm{w}=87)$, and RI and Uni $(\mathrm{w}=85)$. The remaining 35 edges have a weight of 58 or less. Further, 10 edges have a weight of four or less, and one edge has a weight of one.

Figure 15 shows a social network representing W3C collaboration at country level (where a node represents a country and an edge represents collaboration through editorship for two countries). There are in total 129 edges $^{20}$ between 26 different countries, which reflects the degree of diversity in collaboration overall. The degree $d$ of a node represents number of other countries a country has been associated with during organisational collaboration through editorship. The weight $w$ of an edge represents number of standards that two countries (represented by the connected nodes) have collaborated in through editorship. The weighted degree $w d$ represents the sum of weights for edges connected to a node. The top 15 countries in terms of collaboration (measured by weighted degree) are (in descending order) US ( wd = 707, $d=25), G B(w d=254, d=16), D E(w d=$ $191, d=18)$, FR ( $w d=142, d=18), J P(w d=98, d=12)$, CA ( $w d=88, d=12)$, IE ( $w d=81, d=12), F I(w d=80, d=$ $12), \mathrm{NL}(w d=66, d=14), \mathrm{NO}(w d=60, d=13), \mathrm{ES}(w d=$ 60, $d=13), \mathrm{SE}(w d=45, d=14), \mathrm{CH}(w d=44, d=15)$, IT $(w d=34, d=7)$, and AT ( $w d=30, d=11)$. The top five pairs of countries collaborating most extensively are GB and US $(\mathrm{w}=171)$ followed by DE and US $(\mathrm{w}=104)$, US and FR $(\mathrm{w}=62)$, US and CA $(\mathrm{w}=56)$, and US and JP $(\mathrm{w}=$ 54). The remaining 124 edges have a weight of 43 or less. In fact, 86 edges have a weight of three or less, and 39 edges have a weight of one.

In summary, it is clear that there is extensive collaboration between different organisations, types of organisations, and countries. At organisation type level, results show that larger enterprises have the most extensive collaboration with other organisation types.

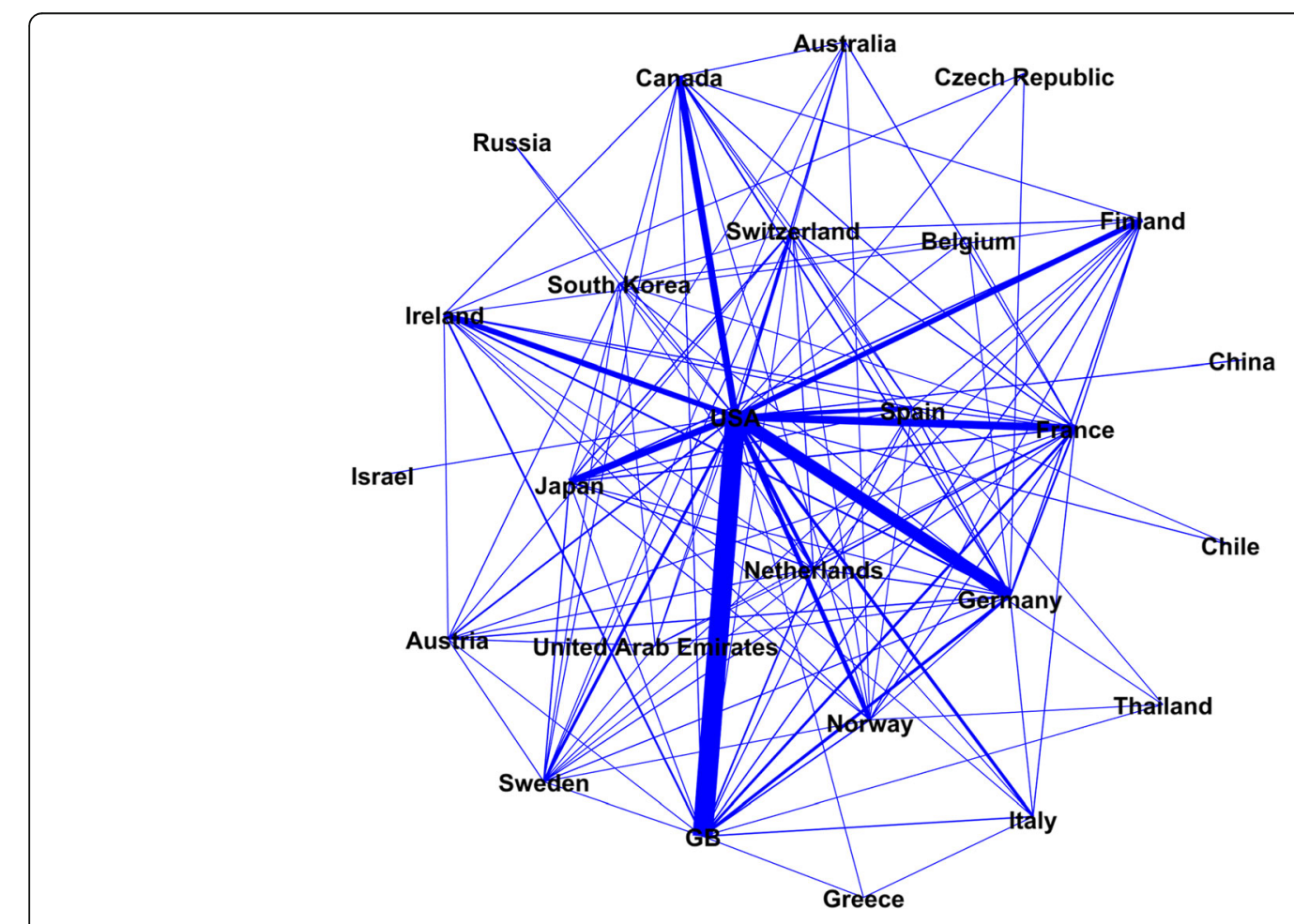

Fig. 15 W3C collaboration at country level 
Further, it is shown that larger enterprises and universities collaborate most extensively. At country level, results show that the United States have the most extensive collaboration with other countries. Further, it is shown that the United States and Great Britain collaborate most extensively. By comparison of the top 15 organisations in terms of involvement (Section 4.1) and the top 15 organisations in terms of collaboration (Section 4.5) we note that 10 out of 15 organisations are in the intersection with similar rankings. This indicates that the majority of organisations with extensive involvement also have extensive collaboration. Similarly, by comparison of the top 15 countries concerning involvement and collaboration it can be noted that 15 out of 15 countries are in the intersection with similar rankings, which indicates that all countries with extensive involvement also have extensive collaboration. Further, by comparing metric values for involvement and collaboration for the organisation types we note that rankings are similar (LE, Uni, SO, and SME are top four types in both cases).

\section{Discussion}

Results from our study open up a number of implications for practice concerning development and use of ICT standards. The study provides rich details concerning organisational involvement in W3C standardisation overall and over time. Such details may provide a valuable basis for informing decision makers in companies and other types of organisations before any strategic decision concerning adoption and involvement in W3C standards. From analysis of W3C standardisation over almost two decades it is apparent that the number of standards which reach the status of recommendation over time has increased. This may be unsurprising given the broader adoption of web technologies and with an increasing number of organisations becoming involved in W3C.

Further, the study provides additional details concerning organisational involvement in different web technologies which aid organisations to better understand how contributions through editorship for specific technologies originate from different organisation types and countries. For example, a small company specialised in a certain niche of web technologies may strategically benefit from these details before becoming actively involved in contributing to specific future web standards that are mission critical for the success of the own business and for improving future competitiveness. In addition, details on organisational involvement in relation to development time are provided which highlight the W3C standards with the shortest and longest development times. Those details may inform potential adopters of those specific W3C standards concerning the pace with which the standards have evolved. Such information may be useful before adopting any such outlier with respect to development time.

The study also presents an overview of organisational collaboration in W3C standardisation in order illuminate how collaboration emerges from interaction between organisations stemming from different organisation types and countries. Overall, this overview showing the existing collaborative ecosystem of W3C standardisation may be useful prior knowledge for an organisation considering engaging in this ecosystem which shapes W3C standards. For example, a research institute based in a specific country may wish to explore the existing collaboration pattern with a view to assess the potential for collaboration with organisations of other types and organisations based in other countries.

The study opens up a number of other implications for development and adoption of W3C standards. For example, aspects related to IPR policies of standards may impact on organisational decisions to contribute to standardisation, and in particular when engaging in a major role such as editorship for a standard. Over the years, different views have been expressed concerning IPR policies for W3C standards and under which conditions such should be licensed and provided. It can be noted that the $\mathrm{W} 3 \mathrm{C}$ has had an emphasis on royaltyfree web standards since its origin, as elaborated by Bekkers and Updegrove [3]: "Early in the development and deployment of the Web, and partly as a result of Berners-Lee's decision not to patent its underlying technology, a culture of free license rights for Web infrastructure developed and took firm hold. Concurrently, open source software became increasingly commonly used to provide the software 'stack' supporting the servers that enable the Web's existence. The result was the adoption by W3C in 2003 of an extremely license fee intolerant Patent Policy" (p. 27). Such a patent policy promotes open collaboration amongst companies, as noted by Rosen [34]: "When major software companies cooperate openly to develop industry standards in organizations like W3C and IETF, few of them have much incentive to demand royalties or impose burdens on competing implementations" (p. 7).

However, it should be noted that the W3C has been involved in "a huge argument over the possible introduction of [F]RAND compared to its previous 'strict RF' (i.e., no royalties or lump sums) patent licensing", even though this was soon resolved in favour of a strict royalty-free licensing ([27], p. 83, 84). One may conjecture that once this tension was resolved, the royalty-free licensing policy adopted by the W3C has not inhibited companies of different sizes to continue to contribute to standard projects over the last decade. Tension concerning IPR for standards is not 
unique for $\mathrm{W} 3 \mathrm{C}$, and it has been stressed that "controversies over intellectual property (IP) rights in standards have been common in the past decade" ([35], p. 27 ), which may significantly impact on organisational involvement in standardisation.

\section{Conclusions and future work}

Findings from the study show that the vast majority of W3C standards have involvement from more than one organisation (often involving collaboration between smaller and larger organisations) with respect to editorship, which is a strong indication of the open and inclusive nature of $\mathrm{W} 3 \mathrm{C}$ standardisation. Further, findings show that involvement and collaboration in many cases include international participation from organisations with headquarters in a variety of different countries.

The study also shows that involvement stems from organisations from countries with a majority of native English speaking citizens, something which may be unsurprising given that all standards are written in English. It is also shown that larger enterprises and smaller commercial organisations provide a major contribution to standardisation, both in terms of involvement and collaboration.

In conclusion, our study establishes novel details on, and promotes understanding of, organisational involvement and collaboration in open standards development. The findings from our study make a contribution which is important for informing any future policy and organisational decisions concerning involvement in standardisation.

One possible direction for future work is to explore new metrics and approaches for data analysis. For example, sub-community detection algorithms could potentially be used to reveal more detailed collaboration patterns in the social network analysis part. Further, machine learning approaches such as decision trees could help create explanatory models. Other types of data sources could be used. We acknowledge that only editorship has been considered in our study. Accounting for working group participation in W3C standards development could provide for a richer picture of involvement and collaboration. It could also be useful to explore individual contributions to the different standards (e.g. through use of issue tracker data). Further, a comparative study including standards developed in other standardisation organisations (e.g. OASIS or IETF) could reveal similarities and differences in involvement and collaboration between different contexts of standardisation. It could also be useful to deeper and more qualitatively explore involvement and collaboration for a few of the specific W3C standards using a case study approach that may also involve interviews.
Further, active participation in W3C standardisation by researchers may aid to design novel and innovative research studies in order to advance research and practice in the field.

\section{Endnotes}

${ }^{1}$ For an overview of outcomes from an ETSI summit on standardisation and open source, see conclusions from the ETSI general chair [21] and a position statement presented during the summit by the W3C Legal counsel [46]. Further, an ETSI workshop addressed legal aspects of using open source in standardisation with an invited panel comprising experts from standardisation and open source communities. See Lundell et al. [31] for an overview of the issues discussed from different experiences and perspectives.

${ }^{2}$ For a position statement presented during the ANSI event by the W3C representative, see Seltzer [37].

${ }^{3}$ Bekkers and Updegrove [3] present a comprehensive analysis of work practices and IPR policies used by different standardisation organisations, which include an analysis of W3C.

${ }^{4}$ Since the origin of the web, provision of standards under royalty-free conditions has been central for W3C. As noted by Bekkers and Updegrove [3]: "Royalty-free standards set low IP and no cost barriers to universally interoperable implementation and use, making them a good fit with the globally distributed, permission-free nature of the Web."

${ }^{5}$ According to Simcoe [38]: "IETF and W3C have many similar features and a few salient differences."

${ }^{6}$ http://www.w3.org/TR/tr-date-stds

${ }^{7}$ https://www.linkedin.com/

${ }^{8}$ https://en.wikipedia.org

${ }^{9}$ https://www.google.com

${ }^{10}$ https://www.w3.org/TR/tr-technology-stds\#w3c_all

${ }^{11}$ https://api.w3.org/, https://w3c.github.io/w3c-api/

${ }^{12}$ https://gephi.org/

${ }^{13}$ https://en.wikipedia.org/wiki/ISO_3166-1_alpha-2

${ }^{14}$ According to https://en.wikipedia.org/wiki/Englishspeaking_world

${ }^{15} \mathrm{We}$ acknowledge that due to time of data collection, five months remain for 2016

${ }^{16}$ This test was chosen since it does not assume any specific data distribution and allows for comparison between sets with different (and also very small) sample sizes.

${ }^{17}$ A fully connected network would comprise 26106 edges.

${ }^{18}$ Five of the 234 organisations reported in section 4.1 have not collaborated with other organisations and therefore the network contains 229 nodes

${ }^{19}$ A fully connected network would comprise 45 edges.

${ }^{20} \mathrm{~A}$ fully connected network would comprise 325 edges. 


\section{Appendix - W3C technologies}

Table 12 Rank number (T1 through T89) for a technology is based on number of times an organisation has contributed through editorship to a standard that is mapped to that technology (shown in brackets after the standard name)

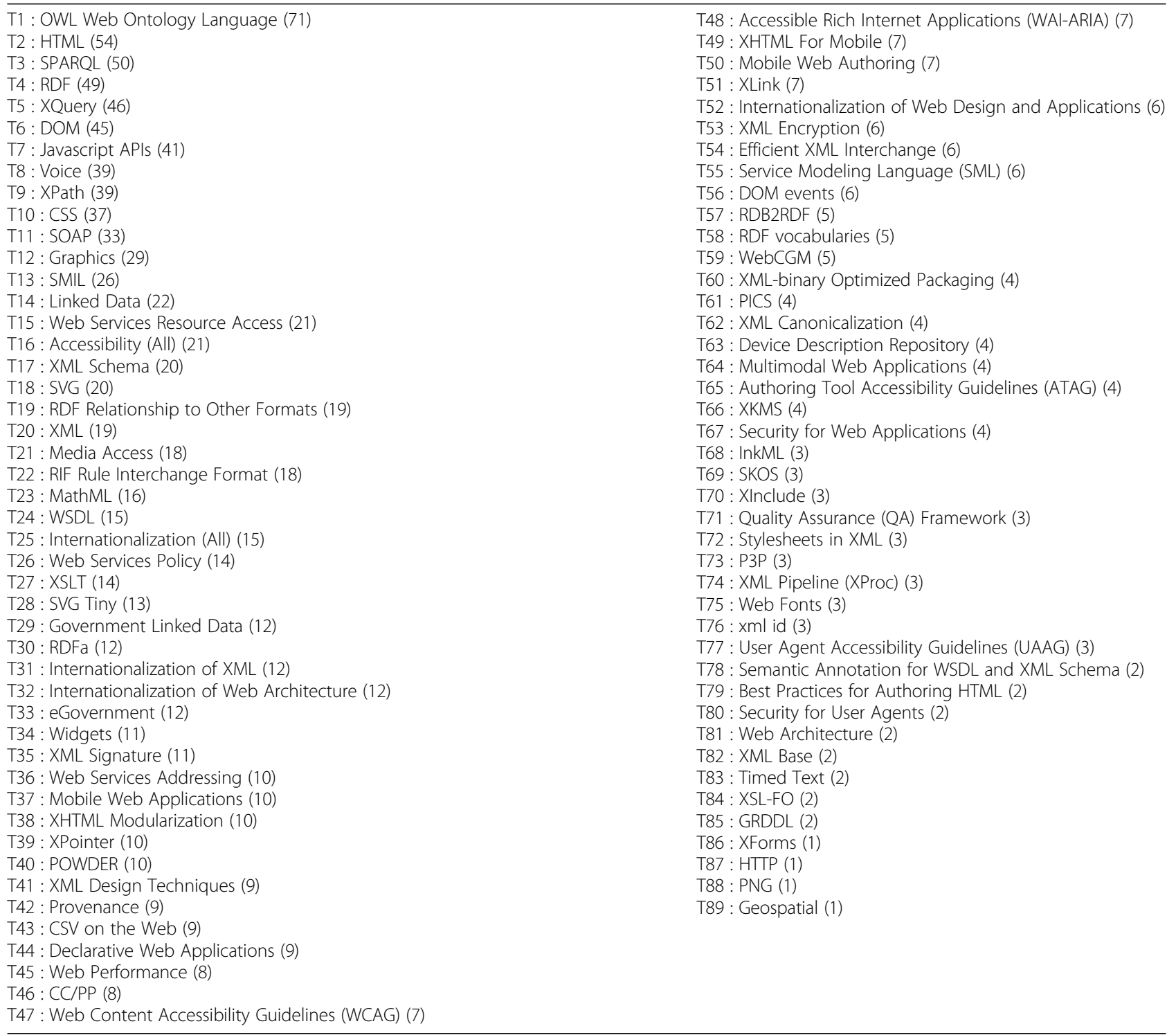

\section{Abbreviations}

[F]RAND: [Fair], Reasonable, And Non-Discriminatory terms; ANSI: American National Standards Institute; API: Application Programming Interface; CEO: Chief Executive Officer; CERN: Conseil Européen pour la Recherche Nucléaire; ECMA: European Computer Manufacturers Association;

ETSI: European Telecommunications Standards Institute; EU: European Union; H: Hospital; ICT: Information and Communication Technology; IETF: Internet Engineering Task Force; IP: Intellectual Property; IPR: Intellectual Property Rights; ISO: International Organization for Standardization; ITU: International Telecommunication Union; ITU-T: ITU Telecommunication standardization sector; LE: Larger Enterprise; MiE: Micro Enterprise; MIT: Massachusetts Institute of Technology; NPO: Non-profit Organisation; OASIS: Organization for the Advancement of Structured Information Standards; PBS: Public Broadcasting Service; RI: Research Institute; SME: Small and Medium-sized Enterprise; SO: Standardisation Organisation; Uni: University; W3C: World Wide Web Consortium; : Standards names mentioned in the manuscript are not considered abbreviations, and are therefore not included in the list.
For explanations of standard names, see W3C (www.w3.org/TR/tr-date-stds).; : Country codes mentioned in the results section are not considered abbreviations, and are therefore not included in the list. For explanations of country codes, see e.g. https://en.wikipedia.org/wiki/ISO_3166-1_alpha-2

\section{Acknowledgements}

There is no additional individual or organisation that has contributed to this manuscript.

\section{Funding}

This research has been internally funded by the University of Skövde, Sweden, which has funded the design of the study, data collection, interpretation of data \& analysis, and preparation of the manuscript.

\section{Authors' contributions}

The authors have contributed equally to all material in the manuscript. Both authors read and approved the final manuscript. 


\section{Competing interests}

The authors declare that they have no competing interests.

\section{Ethics approval and consent to participate}

Not applicable.

\section{Publisher's Note}

Springer Nature remains neutral with regard to jurisdictional claims in published maps and institutional affiliations.

Received: 31 August 2016 Accepted: 26 April 2017

Published online: 11 May 2017

\section{References}

1. Allman E. The robustness principle reconsidered: seeking a middle ground. Commun ACM. 2011;54(8):40-5.

2. Behlendorf $B$. How open source can still save the world, keynote presentation. In: 5th IFIP WG 2.13 International Conference on Open Source Systems, OSS 2009, Skövde, Sweden, 5 June, 2009. 2009.

3. Bekkers $\mathrm{R}$, Updegrove A. IPR policies and practices of a representative group of standards-setting organizations worldwide, commissioned by the committee on intellectual property management in standard-setting processes. Washington: National Research Council; 2013.

4. Bonaccorsi A, Rossi C. Comparing motivations of individual programmers and firms to take part in the open source movement: from community to business, Knowledge. Technol Policy. 2006;18(4):40-64.

5. Bos B. Why standards? \& current CSS topics, DTO Seminar from the Inventor of CSS, Canberra, ACT, Australia, 4 February 2016. 2016. https://www.w3.org/ Talks/2016/0204-W3C-Canberra/. Accessed 5 Jan 2017.

6. BSI. Pocket Guide to Standards Development, BSI: British Standards Institution. 2017. https://www.bsigroup.com/Documents/about-bsi/NSB/BSIpocket-guide-to-standards-development-UK-EN.pdf. Accessed 5 Jan 2017.

7. Choi B, Raghu TS, Vinze A. Addressing a standards creation process: a focus on ebXML. Int J Hum Comput Stud. 2004;61(5):627-48.

8. Contreras JL. Divergent patterns of engagement in Internet standardization: Japan, Korea and China. Telecommun Policy. 2014:38(10):914-32.

9. Dickerson K. The Paramount Importance of Standards to Operators, Vendors and Users, Keynote Address. Keynote speech at the 4th International Conference on Standardization and Innovation in Information Technology. Geneva: SIIT; 2005.

10. European Commission (EC). Press Release, Digital Agenda: Open standards would save public sector $€ 1$ billion a year, Brussels, 25 June. 2013. http://europa.eu/rapid/press-release_IP-13-602_en.htm. Accessed 5 Jan 2017.

11. EC. Rolling plan for ICT standardisation 2015. Brussels: European Commission; 2015

12. Fitzgerald B. The transformation of open source software. MIS Q. 2006:30(4):587-98

13. Friedrich J. Making innovation happen: the role of standards and openness in an innovation-friendly ecosystem. In: 7th International Conference on Standardization and Innovation in Information Technology (SIIT). Piscataway: IEEE; 2011. p. 1-8.

14. Gamalielsson J, Lundell B. Experiences from implementing PDF in open source: challenges and opportunities for standardisation processes. In: Jakobs K, editor. Proceedings of the 8th IEEE Conference on Standardization and Innovation in Information Technology (SIIT 2013), ISBN 3-86130-802-9. Piscataway: IEEE; 2013. p. 39-49.

15. Gamalielsson J, Lundell B, Lings B. The Nagios community: an extended quantitative analysis. In: Agerfalk $P$ et al., editors. Open source software: New Horizons. Berlin: Springer; 2010. p. 85-96.

16. Gamalielsson J, Lundell B, Mattsson A. Open source software for model driven development: a case study. In: Hissam S, editor. Open source systems: grounding research, IFIP advances in information and communication technology, vol. 365. Boston: Springer; 2011. p. 348-67. ISBN: 978-3-642-24417-9.

17. Gamalielsson J, Lundell B, Grahn A, Andersson S, Feist J, Gustavsson T, Strindberg $\mathrm{H}$. Towards a reference model on how to utilise open standards in open source projects: experiences based on Drupal. In: Petrinja E et al., editors. Open source software: quality verification, IFIP advances in information and communication technology, vol. 404. Heidelberg: Springer; 2013. p. 257-63. ISBN 978-3-642-38928-3.
18. Gamalielsson J, Lundell B, Feist J, Gustavsson T, Landqvist F. On organisational influences in software standards and their open source implementations. Inf Softw Technol. 2015;67:30-43.

19. Gloor PA, Laubacher R, Dynes SBC, Zhao Y. Visualization of communication patterns in collaborative innovation networks - analysis of some W3C working groups. In: Proceedings of the Twelfth International Conference on Information and Knowledge Management (CIKM '03), ACM, 2003. 2003. p. 56-60.

20. Griset $P$, Schafer V. Hosting the World Wide Web Consortium for Europe: from CERN to INRIA. Hist Technol. 2011;27(3):353-70.

21. Hicks R. Conclusions on ETSI workshop on Standardization and Open source. In: ETSI Summit on Standardization and Open source, 19 November. Sophia Antipolis, France; 2015. https://docbox.etsi.org/Workshop/2015/ 201511_OPENSOURCESUMMIT/O0ETSISUmmit2015_Conclusions.pdf.

22. Jakobs K. ICT standards research - Quo Vadis? Homo Oeconomicus. 2006;23(1):79-107

23. Jakobs K. Managing corporate participation in international ICT standards setting. In: Proceedings of the International Conference on Engineering, Technology and Innovation (ICE 2014), IEEE, 2014. 2014. p. 1-12.

24. Jakobs K. The (future) role of China in ICT standardisation - A European perspective. Telecommun Policy. 2014;38(10):863-77.

25. Jakobs K. Trust in open standardisation?! In: Proceedings of XXVIII sinergie annual conference on management in a digital world. Decisions, production, communication. Italy: University of Udine; 2016. p. 9-10.

26. Krechmer K. Recommendations for the global information highway: a matter of standards. StandardView. 1996;4(1):24-8.

27. Lea G, Hall P. Standards and intellectual property rights: an economic and legal perspective. Inf Econ Policy. 2004;16(1):67-89.

28. Linåker J, Rempel P, Regnell B, Mäder P. How firms adapt and interact in open source ecosystems: analyzing stakeholder influence and collaboration patterns. In: Daneva P, Pastor O, editors. Requirements engineering: foundation for software quality, lecture notes in computer science, vol. 9619. New York: Springer-Verlag New York, Inc.; 2016. p. 63-81. ISBN: 978-3-319-30281-2.

29. Lundell B. e-Governance in public sector ICT procurement: what is shaping practice in Sweden? Eur J ePractice. 2011;12:66-78.

30. Lundell B. Why do we need open standards? In: Orviska M, Jakobs K, editors. Proceedings 17th EURAS annual standardisation conference 'standards and innovation'. Aachen: The EURAS Board Series; 2012. p. 227-40. ISBN: 978-3-86130-337-4.

31. Lundell B, Marr D, Opie E, Piana C, van Rooijen A. Panel discussion: Standpoint of the standardization community having a FRAND policy concerning the use of open source \& standpoint of the open source community to work with deliverables coming from the standardization world, 16 September. Sophia Antipolis: ETSl; 2016.

32. Lundell B, Gamalielsson J, Katz A. On implementation of open standards in software: to what extent can ISO standards be implemented in open source software? Int J Stand Res. 2015;13(1):47-73.

33. Lundell B, Gamalielsson J, Grahn A, Feist J, Gustavsson T, Strindberg H. On influences between software standards and their implementations in open source projects: Experiences from RDFa and its implementation in Drupal. In: Proceedings of the 10th International Symposium on Open Collaboration, OpenSym 2014. New York: ACM; 2014. p. 3:1. ISBN 978-1-4503-3016-9, article 3.

34. Rosen L. Implementing open standards in open source. Comput Internet Lawyer. 2011;28(4):5-8

35. Samuelson P. Copyrighting standards. Commun ACM. 2006;49(6):27-31.

36. Schaarschmidt M, Walsh $G$, von Kortzfleisch HFO. How do firms influence open source software communities? A framework and empirical analysis of different governance modes. Inf Organ. 2015;25(2):99-114.

37. Seltzer W. World Wide Web Consortium (W3C) Standards for the Open Web Platform. In: "Open source, open standards, open minds", ANSI, 15 April, Washington DC. 2016.

38. Simcoe T. Modularity and the evolution of the internet. In: Goldfarb A, Greenstein SM, Tucker CE, editors. Economic analysis of the digital economy, ISBN: 0-226-20684-X; 978-0-226-20684-4. Chicago: University of Chicago Press; 2015. p. 21-47.

39. Spring MB, Grisham C, O'Donnell J, Skogseid I, Snow A, Tarr G, Wang P. Improving the standardization process: working with bulldogs an turtles. In: Kahin B, Abbate J, editors. Standards policy for information infrastructure. Boston: MIT Press; 1995. p. 220-52. 
40. Stevens L, Owen RJ. A somewhat sensationalized history of HTML5. In: The truth about HTML5. Berkeley: Apress; 2014. p. 1-12.

41. Teixeira J, Robles G, González-Barahona JM. Lessons learned from applying social network analysis on an industrial Free/Libre/Open Source Software ecosystem. J Internet Serv Appl. 2015;6(14):1-37.

42. UK. Open Standards Principles: For software interoperability, data and document formats in government IT specifications, HM Government, UK. 2012. https://www.gov.uk/government/uploads/system/uploads/ attachment_data/file/183962/Open-Standards-Principles-FINAL.pdf. Accessed 5 Jan 2017.

43. UK. Open Standards Principles: For software interoperability, data and document formats in government IT specifications, HM Government, UK. 2015. https://www.gov.uk/government/uploads/system/uploads/ attachment_data/file/459075/OpenStandardsPrinciples2015.pdf. Accessed 5 Jan 2017.

44. W3.org. About W3C. 2016a. http://www.w3.org/Consortium/. Accessed 22 Aug 2016.

45. W3.org. Current Members. 2016b. https:/www.w3.org/Consortium/Member/ List. Accessed 4 Jan 2017.

46. Wenning R. Standards that help converge Open source, In ETSI Summit on Standardization and Open source, 19 November. Sophia Antipolis, France; 2015. https://docbox.etsi.org/Workshop/2015/201511_ OPENSOURCESUMMIT/W3C_WENNING.pdf.

47. West J, O'Mahony S. The role of participation architecture in growing sponsored open source communities. Ind Innov. 2008;15(2):145-68.

\section{Submit your manuscript to a SpringerOpen ${ }^{\mathcal{O}}$ journal and benefit from:}

- Convenient online submission

- Rigorous peer review

- Immediate publication on acceptance

- Open access: articles freely available online

- High visibility within the field

- Retaining the copyright to your article

Submit your next manuscript at $\boldsymbol{s p r i n g e r o p e n . c o m ~}$ 